\title{
TAXONOMÍA DE LOS GASTERÓPODOS TERRESTRES DEL CUATERNARIO DE ARGENTINA
}

\author{
Sergio Eduardo MIQUEL $L^{1,2}$ y Marina Laura AGUI- \\ $R R E^{1,3}$ \\ ${ }^{1}$ CONICET (Consejo Nacional de Investigaciones Científicas y Técnicas). \\ ${ }^{2}$ Museo Argentino de Ciencias Naturales "Bernardino Rivadavia", Av. Án- \\ gel Gallardo 470, 1405 Ciudad Autónoma de Buenos Aires, Argentina; \\ semsnail@yahoo.com.ar \\ ${ }^{3}$ Facultad de Ciencias Naturales y Museo, Universidad Nacional de La Plata; \\ Edificio Institutos, Laboratorios y Cátedras, calle 64 № 3, 1900 La Plata, Ar- \\ gentina; maguirre@fcnym.unlp.edu.ar
}

Miquel, S. E. \& Aguirre, M. L. 2011. Taxonomía de los gasterópodos terrestres del Cuaternario de Argentina. [Taxonomy of terrestrial gastropods from the Quaternary of Argentina.] Revista Española de Paleontología, 26 (2), 101-133. ISSN 0213-6937.

\begin{abstract}
This systematic review synthesizes our updated knowledge of 33 species and subspecies of Stylomatophoran gastropods, which belong to the genera Gastrocopta, Succinea, Radiodiscus, Retidiscus, Rotadiscus, Cecilioides, Austroborus, Megalobulimus, Bulimulus, Discoleus, Naesiotus, Plagiodontes, Spixia, Scolodonta, Miradiscops and Epiphragmophora. We provide published and unpublished records of the terrestrial molluscan taxa and a critical review, including data from the most important collections deposited in institutions from Argentina and abroad. All the taxa described have modern representatives; only two, Succinea rosariensis and Scolodonta argentina, still require confirmation regarding their taxonomic validity. The genera with confirmed older than Quaternary records are Austroborus, Megalobulimus, Radiodiscus, Rotadiscus and Succinea, which occur since the Paleogene. Regarding the modern geographical distribution, well known records involve part of Argentina (Subtropical and Pampean Dominia of the Guayanian-Brazilian Subregion and the Central Dominion of the Andean Subregion, both in the Neotropical Region). The best-known fraction of the fossil molluscs recovered corresponds to species of medium to large-size dimensions, whereas taxa of less than $5 \mathrm{~mm}$ have very seldom been mentioned before. Approximately $60 \%$ of the species recorded belong to the Orthalicidae (=Bulimulidae), the Strophocheilidae represent ca. 15\%, while other families like the Xanthonychidae, Charopidae and Scolodontidae provide ca. $10 \%$ each. This review made evident that the main contributions on this subject were published by Joaquín Frenguelli who was responsible for having formed and organize the most important Quaternary terrestrial collection from Argentina, made of over a hundred lots deposited at the Museo de La Plata (Invertebrate Palaeontology Department). The synthesis on the distribution and ecological requirements of the taxa identified provide the basic source of reference necessary to carry out future palaeoenvironmental and palaeoclimatical interpretations, complementary of research work performed based on mammals, pollen and phytoliths, as well as to select significative and reliable taxa for geochronological and isotope analyses on shells from Neogene sediments traditionally known as chronostratigraphical units (Platense, Cordobense, Bonaerense, Ensenadense of the local literature).
\end{abstract}

Keywords: Gastropoda, Pleistocene, Holocene, continental, South America, Neotropical, systematic review.

\section{RESUMEN}

Esta revisión sistemática sintetiza el conocimiento actualizado sobre 33 especies y subespecies de gasterópodos estilomatóforos de los géneros Gastrocopta, Succinea, Radiodiscus, Retidiscus, Rotadiscus, Cecilioides, Austroborus, Megalobulimus, Bulimulus, Discoleus, Naesiotus, Plagiodontes, Spixia, Scolodonta, Miradiscops y Epiphragmophora. Aporta los registros editados e inéditos de la malacofauna terrestre, y la revisión de las colecciones de las instituciones nacionales más importantes. Todos los taxones citados están representados en la actualidad; sólo dos de ellos, Succinea rosariensis y Scolodonta argentina, requieren de confirmación acerca de su validez taxonómica. Los géneros que se registran con anterioridad al Cuaternario son Austroborus, Megalobulimus, Radiodiscus, Rotadiscus y Succinea, presentes desde el Paleógeno. En relación con la distribución geo- 
gráfica, los registros conocidos abarcan una parte del territorio argentino (Dominios Subtropical y Pampásico de la Subregión Guayano-Brasileña y Dominio Central de la Subregión Andina; Región Neotropical). La fracción mejor conocida de los moluscos fósiles corresponde a aquellas especies de mediano y gran tamaño, en tanto que resultan escasas las citas de taxones de talla inferior a $5 \mathrm{~mm}$. Cerca del $60 \%$ de las especies registradas pertenecen a la familia Orthalicidae (=Bulimulidae), Strophocheilidae incluye el $15 \%$, en tanto que familias como Xanthonychidae, Charopidae y Scolodontidae aportan, cada una, cerca del 10\% de las especies. Las principales contribuciones en la materia fueron publicadas por Joaquín Frenguelli, responsable de haber formado la colección más importante en la materia, constituida por más de un centenar de lotes, depositada en el Museo de La Plata (Departamento Paleontología Invertebrados). La síntesis sobre distribución y requerimientos ecológicos de los taxones identificados aporta la fuente de información básica necesaria para efectuar futuras interpretaciones paleoambientales y paleoclimáticas, complementarias de trabajos basados en mamíferos y/o polen y fitolitos, así como para seleccionar taxones significativos para estudios geocronológicos e isotópicos sobre conchas contenidas en las unidades estratigráficas del Neógeno conocidas tradicionalmentes como unidades cronoestratigráficas (Platense, Cordobense, Bonaerense, Ensenadense de la literatura local).

Palabras clave: Gasterópodos, Pleistoceno, Holoceno, continentales, Sudamérica, Neotropical, revisión sistemática.

\section{INTRODUCCIÓN}

En Argentina los sedimentos cuaternarios de origen continental (lacustres, fluviales y eólicos) (Figs 1a, 1b) contienen gasterópodos y escasos bivalvos, pocos conocidos desde el siglo XIX, fundamentalmente a partir de ilustraciones y menciones publicadas en obras monográficas clásicas, resultado de expediciones al cono sur de Sudamérica (i.e., d'Orbigny, 1835, 1834-1847), y de catálogos locales (i.e., Camacho, 1967) o a través de listas mencionadas en trabajos de índole geológica (i.e., Frenguelli, 1957). A ellos se suman estudios más modernos enfocados sólo a especies o grupos taxonómicos particulares y generalmente de sitios puntuales (Miquel \& Steffan, 2005; De Francesco et al., 2007; Aguirre et al., 2011).

En especial la malacofauna terrestre preservada en depósitos del Neógeno de Argentina ha sido en su conjunto, en términos generales, comparativamente poco estudiada con respecto a la marina, existiendo una enorme brecha entre la información disponible sobre los representantes vivientes (i.e., Fernández, 1973) y los taxones preservados en depósitos del Pleistoceno y Holoceno (i.e., Camacho, 1967). Los registros del Cuaternario son conocidos principalmente a través de autores clásicos del siglo XIX (d'Orbigny, 1835, 1834-1847; Doering, 1873-1907; Holmberg, 1912) y, más recientemente, a través de contribuciones de Frenguelli (i.e., 1918-1957), Hylton Scott (1939-1968), Parodíz (1939-1996), Camacho (1967) y Fernández (1973).

Históricamente, se puede considerar a las contribuciones de Adolfo Doering (Döring en su forma original alemana) como pioneras en el tratamiento del tema en nuestro país, autor que describió unas pocas especies de gasterópodos continentales extintos (1884b,c, 1885). Por su parte, Joaquín Frenguelli fue autor de varias publicaciones durante el período 1918 - 1957 y el responsable de haber formado la colección argentina de moluscos terrestres cuaternarios más importante existente, depositada en el Museo de La Plata. El más reciente aporte en esta materia fue el realizado por Horacio Camacho (1967), quien dió a conocer en su catálogo de invertebrados fósiles de la provincia de Buenos Aires especies de los géneros Succinea Draparnaud, Megalobulimus Miller, Bulimulus Leach, Discoleus Breure, Plagiodontes Doering, Spixia Pilsbry \& Vanatta y Scolodonta Doering.

Curiosamente, sólo una parte del sector continental argentino cuenta con registros de taxones cuyo material de referencia puede localizarse con relativa facilidad por encontrarse depositado en colecciones nacionales y/o extranjeras (i.e., MACN, MLP, NHMUK [ex BMNH], MNHN), principalmente proveniente de sitios o áreas que corresponden a las unidades biogeográficas conocidas como Dominio Subtropical y Dominio Pampásico (Subregión Guayano-Brasileña) y Dominio Central (Subregión Andina) de la Región Neotropical (sensu Ringuelet, 1961) (Fig. 1b). Probablemente esta situación obedezca a razones históricosociales, como la disponibilidad de vías de acceso y poblaciones de aquellos sectores en comparación con la situación de mayor aislamiento de la Patagonia. Por otro lado, más recientemente el cambio metodológico de recuperación de material fósil ha permitido recientemente la identificación de mayor diversidad dentro de la fracción de los micromoluscos (Miquel \& Steffan, 2005; De Francesco et al., 2007), no reconocida o subestimada y prácticamente ausente en las obras tradicionales locales hasta fines del siglo XX.

Dada la inexistencia de una obra moderna de síntesis sobre la malacofauna terrestre del Cuaternario de Argentina, hasta hoy conocida sólo a través de fuentes de información dispersa para grupos, áreas y rangos temporales particulares, el objetivo de este trabajo es reunir, ordenar y actualizar el conocimiento sistemático referido a los taxones representativos, de acuerdo con la información disponible hasta el momento.

La información aquí reunida resultará de utilidad a paleontólogos, arqueólogos, geólogos y biólogos que, sin ser 
especialistas en la materia, puedan identificar con eficacia los materiales de gasterópodos terrestres recuperados en los muestreos, minimizando la posibilidad de errores taxonómicos y/o en la caracterización de los hábitats y modos de vida de las especies, como ha ocurrido en trabajos de índole geológica y arqueológica (Andreis, 1977).

Esta revisión y síntesis documenta e ilustra registros de 35 taxones de gasterópodos, de los cuales 33 están determinados a nivel específico, e incluye registros editados e inéditos de esta malacofauna y la revisión de materiales de las principales colecciones del país, así como ejemplares tipo de instituciones nacionales y extranjeras (véase Materiales y Métodos).

\section{MATERIALES Y MÉTODOS}

En el tratamiento taxonómico de los taxones se incluye la nomenclatura utilizada por los autores clásicos consultados, ya sea en las etiquetas de colección como en la bibliografía, en tanto que para la síntesis bioestratigráfica se adopta el esquema de Cione \& Tonni (2005) y Tonni (2009) y se mantiene la denominación Cuaternario sobre la base de la opinión de la Comisión Argentina de Estratigrafía (Riccardi, 2007). En el tratamiento de la distribución estratigráfica de cada taxón se han respetado las menciones de los registros temporales tal como aparecen en la bibliografía original y en los archivos de las colecciones

\section{Provincia de Buenos Aires (Argentina)}

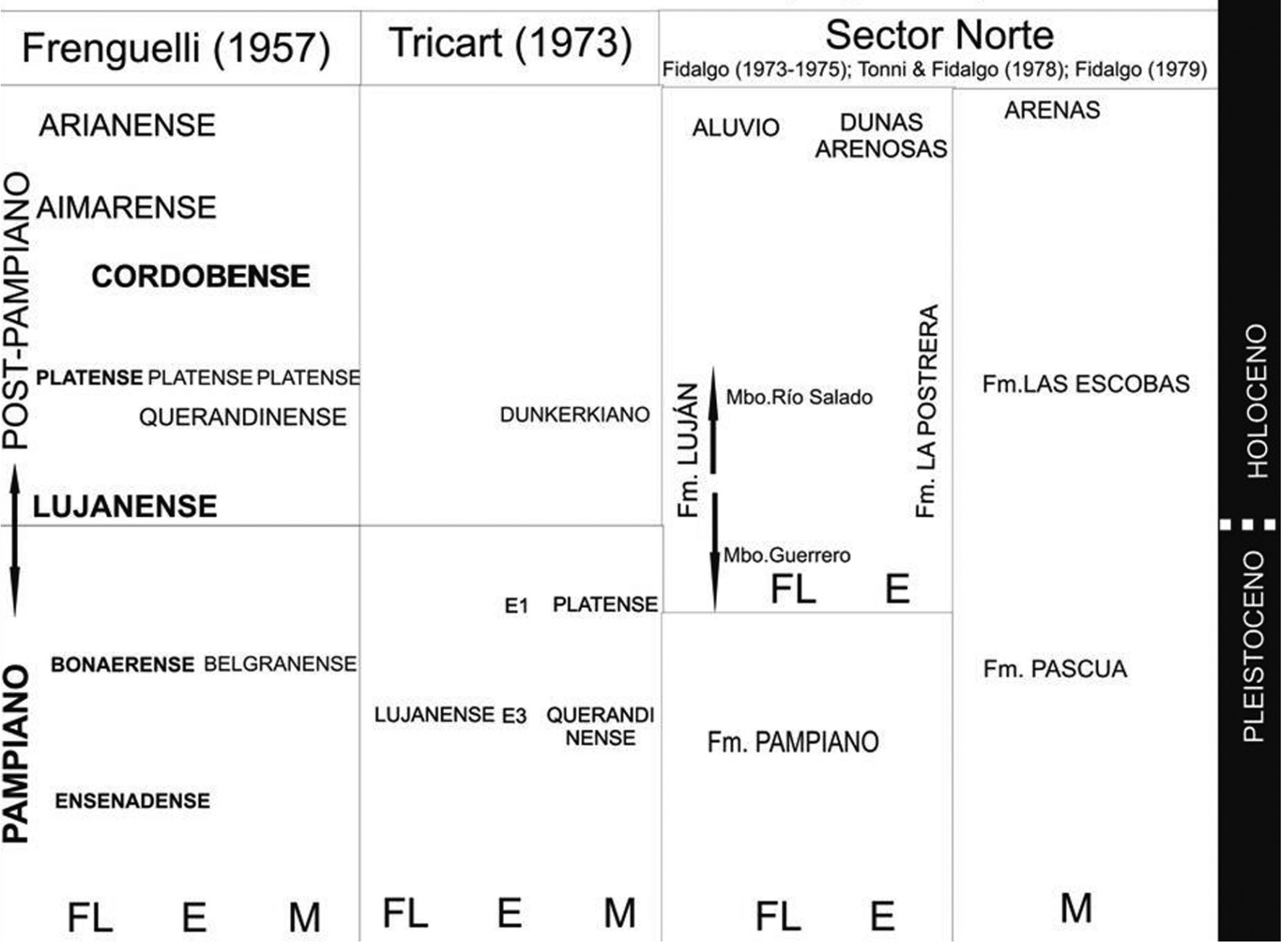

Figura 1a. Síntesis estratigráfica del Cuaternario de Argentina con énfasis en el sector bonaerense (Provincia de Buenos Aires). E: sedimentos eólicos; FL: fluviales; M: marinos. Unidades cronoestratigráficas y litoestratigráficas tradicionales para el sector bonaerense mencionadas en el texto. Fuentes de información bibliográfica en Aguirre \& Whatley (1995), Tonni et al. (1999) y otras referencias allí.

Stratigraphical synthesis of the Quaternary of Argentina with emphasis on the bonaerensian sector (Provincia de Buenos Aires). E: eolian sediments; FL: fluvial; M: marine. Traditional chronostratigraphical and lithostratigraphical units used for the bonaerensian sector and mentioned along the text. Source of references in Aguirre \& Whatley (1995), Tonni et al. (1999) and others cited therein. 
examinadas. En este sentido se ha mantenido, por ejemplo, la nomenclatura de pisos crono-estratigráficos utilizada por Frenguelli (1918 - 1957). No obstante, la validez de estos pisos es local ya que son válidos principalmente para la provincia de Buenos Aires, Córdoba y otras regiones, pero no para otras como la provincia de Mendoza donde recientemente se ha descrito una especie de gasterópodo terrestre (De Francesco et al., 2007 ). Discutir el valor o el alcance de los pisos definidos en la provincia de Buenos Aires excede los objetivos de este trabajo y es por ello que usaremos las denominaciones originales. La equivalencia temporal de los mismos con la escala geocronológica estándar se muestra en la figura 1a. En los últimos años, algunas contribuciones de revisión y reordenamiento estratigráfico de las unidades portadoras utilizaron técnicas de fechado radiocarbónico, las que otorgan mayor precisión temporal a los registros (Tonni et al., 1999; Tonni, 2004, 2009; Cione \& Tonni, 2005 y otras referencias allí).

Para la clasificación taxonómica de las categorías superiores se ha seguido a Bouchet \& Rocroi (2005), en tanto que el glosario se ha confeccionado en base a Oliveira \& Oliveira (1974) y a trabajos en ejecución.

Los materiales estudiados corresponden a recolecciones propias y a material de referencia perteneciente a las siguientes instituciones: DCG-MLP (Departamento Científico Geología - Museo de La Plata), FSC-IN-RQG

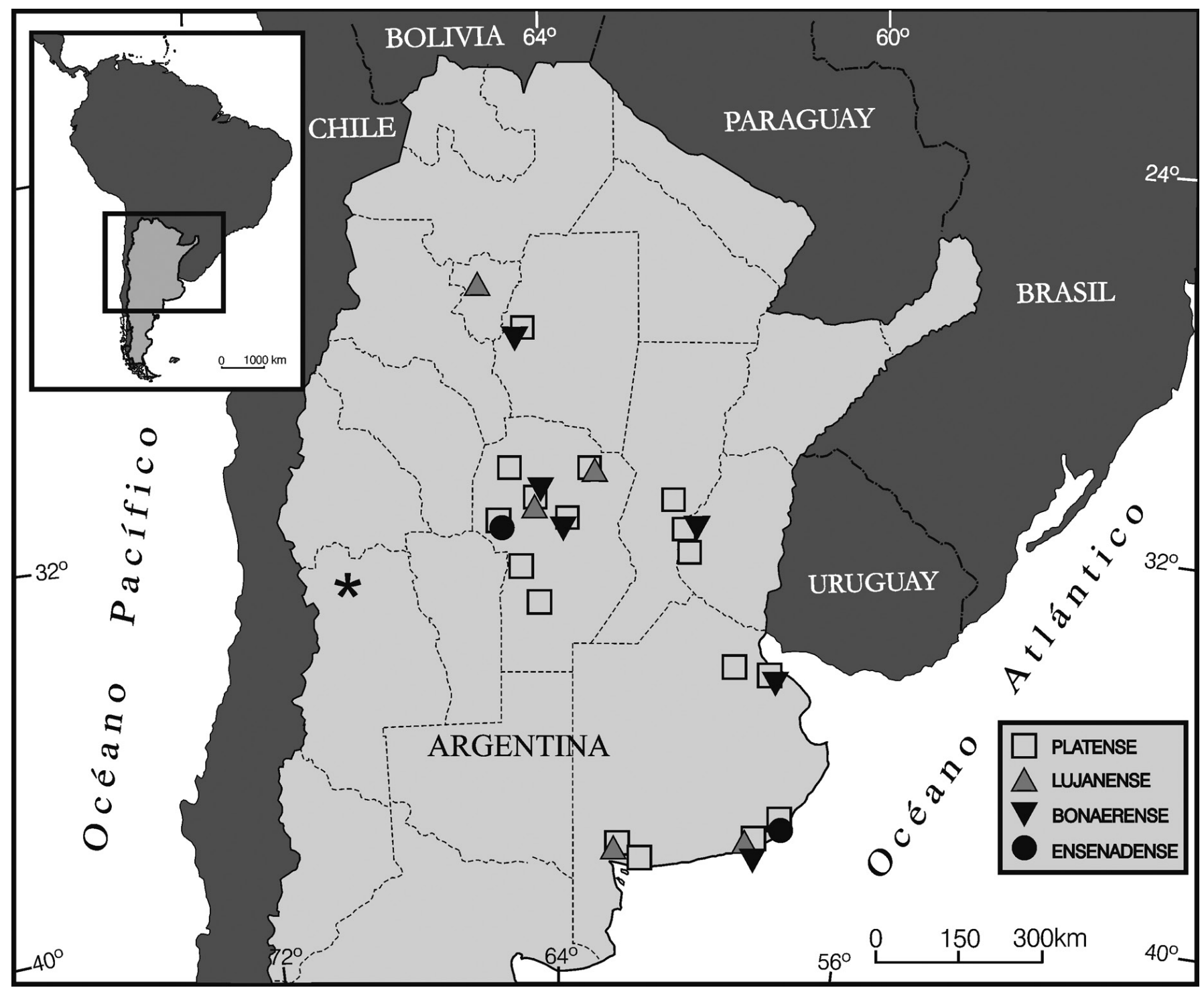

Figura 1b. Mapa de ubicación de las localidades con registros de moluscos de sedimentos cuaternarios continentales, principalmente terrestres. Unidades cronoestratigráficas y litoestratigráficas mencionadas en el texto. *: Registro del Pleistoceno tardío para la provincia de Mendoza.

Location map showing localities with molluscan records in Quaternary continental sediments, mainly terrestrial. Chronostratigraphical and lithostratigraphical units mentioned in the text. *: Record for the Late Pleistocene in Mendoza province. 
(Facultad de Ciencias Sociales de la Universidad Nacional del Centro de la Provincia de Buenos Aires, Invertebrados, Rio Quequén Grande); MACN-In (Museo Argentino de Ciencias Naturales "Bernardino Rivadavia", División Invertebrados); MACN-Pi (Museo Argentino de Ciencias Naturales, División Paleoinvertebrados); MAS PALEOINV (Museo de Ciencias Naturales y Antropológicas "Prof. Antonio Serrano", Paraná, Entre Ríos); MCNZ (Museu de Ciências Naturais da Fundação Zoobotânica do Rio Grande do Sul, Porto Alegre, Brasil); MLP (Museo de La Plata); MNHN: Museum National d'Histoire Naturelle (Paris); NHMUK (Natural History Museum, Londres; ex BMNH); PIL (Colección de Paleontología Invertebrados Lillo); SMF: Forschungsinstitut und Naturmuseum Senckenberg (Frankfurt am Main); UCCC: Colecciones Científicas de la Universidad de Concepción (Chile); ZMB: Museum für Naturkunde Humboldt-Universität (Berlin); J.F.: colección Joaquín Frenguelli (en el MLP). Las abreviaturas utilizadas para las dimensiones del material son: alt: altura; dm: diámetro mayor.

Las edades radiocarbónicas mencionadas para la provincia de Entre Ríos fueron extraídas de Aguirre et al. (2011).

Respecto del estado en que los ejemplares son hallados en los depósitos fosilíferos, es frecuente encontrar las conchas completas o casi completas, con excelente grado de preservación, y, aún mismo, preservando su microescultura embrionaria, por lo que, muchas veces, se logra una determinación exacta o bastante aproximada. No obstante, pueden encontrarse fragmentos poco identificables, aún para los especialistas (restos de la última vuelta, columela, labio externo, ápices rodados, etc). Ciertas estructuras, como la coalescencia de las paredes internas de dos vueltas conquiliares, permiten reconocer esos fragmentos como pertenecientes a un gasterópodo, aunque no posibilitan avanzar en la determinación del género o especie al que corresponden.

Por otra parte, para la observación detallada de las microesculturas es fundamental realizar observaciones por medio de microscopía electrónica, aunque la sola metalización y consecuente análisis de la pieza con instrumentos ópticos suele bastar para conseguir la identificación del ejemplar. En los gasterópodos de forma discoide es conveniente la observación de la protoconcha desde la región umbilical ya que, adecuadamente limpiada, mantiene los rasgos intactos de su microescultura.

La mayor parte de las ilustraciones corresponden a ejemplares medianos o grandes, fotografiados a cámara digital en tanto que los micromoluscos se ilustran mediante fotografías de microscopio electrónico de barrido (equipo del Museo Argentino de Ciencias Naturales "Bernardino Rivadavia"), en un caso se reproduce la figura original de Doering. A efectos de la limpieza, observación e ilustración de los especímenes se utilizaron equipos de limpiadora ultrasónica (Lilis 3.8), lupa binocular (Nikon SMZ1000) con cámara digital adosada (Nikon Colpix S10 VR) y cámara digital (Nikon D3100).
En las listas sinonímicas se emplean signos no nomenclatotiales, de acuerdo a Matthews (1973).

Para una rápida discriminación de los materiales a identificar, se propone utilizar la siguiente clave simplificada:

1. De pequeño tamaño (menor a $10 \mathrm{~mm}$ )

A. Altura mayor que el diámetro máximo a. sin dientes o lamelas en la abertura: Ferussaciidae Cecilioides Férussac

b. con dientes o lamelas en la abertura: Pupillidae Gastrocopta Wollaston

B. Diámetro máximo mayor que la altura a. con delimitación neta de proto y teleoconcha y algún tipo de escultura en proto- o teleoconcha o en ambas: Charopidae: Radiodiscus Pilsbry \& Ferriss, Retidiscus Fonseca \& Thomé y Rotadiscus Pilsbry. b. sin delimitación entre proto y teleoconcha y lisos: Scolodontidae Scolodonta y Miradiscops Baker

2. De tamaño mediano a grande (mayor a $10 \mathrm{~mm}$ ) a. la última vuelta ocupa $3 / 4$ partes de la altura: Succineidae Succinea

b. la última vuelta de alrededor de la mitad de la altura, sólidas, globosas, con labro reflejado, protoconcha sin escultura: Strophocheilidae Austroborus Parodiz y Megalobulimus

c. la última vuelta ocupa la mitad de la altura, frágiles, fusiformes, sin labro reflejado, protoconcha con escultura: Orthalicidae Bulimulinae Bulimulus, Discoleus y Naesiotus Albers; y Odontostominae Plagiodontes y Spixia

d. De forma helicoide baja: Xanthonychidae Epiphragmophora Doering

Se ha confeccionado un glosario (véase Apéndice) que sintetiza los términos de la morfología utilizados en este trabajo.

\section{PALEONTOLOGÍA SISTEMÁTICA}

Phylum MOLLUSCA Linné, 1758

Clase GASTROPODA Cuvier, 1797

Subclase PULMONATA Cuvier, 1817

Orden STYLOMMATOPHORA Schmitt, 1855

Superfamilia Pupilloidea Turton, 1831

Familia Pupillidae Turton, 1831

\section{Gastrocopta Wollaston, 1878}

Especie tipo: Pupa acarus Benson, 1856.

Sinónimos: Véase Pilsbry (1948: 870).

Distribución estratigráfica: Paleoceno? - Reciente (Tracey et al., 1993). Plioceno - Reciente (Zilch, 1959-60).

Distribución estratigráfica en Argentina: Holoceno tardío - Reciente (Tonni et al., 2001; Aguirre et al., 2011). 


\section{Gastrocopta nodosaria (d'Orbigny, 1835)}

Fig. 2

*1835. Helix nodosaria d'Orb.: 22.

1837. Pupa nodosaria (d'Orb.); d'Orb.: 322 pl. 41 bis, figs. 12-14.

1916. Gastrocopta nodosaria (d'Orb.); Pilsbry: 94, pl. 17, fig. 10.

1997. Gastrocopta iheringi (Suter); Miquel \& Parent: 108 , fig. 7.

v2001. Gastrocopta nodosaria (d'Orb.); Tonni et al.: 2 .

v2011. Gastrocopta nodosaria (d'Orb.); Aguirre et al.: 8, fig. $4(18,19)$.

Descripción: Concha pequeña, cilíndrico-oblonga, umbilicada, de espira alargada, ápice obtuso, con $51 / 2-6$ vueltas convexas de crecimiento lento, con la última vuelta menor a la mitad del largo total, sutura profunda, abertura subcircular que muestra 5 estructuras internas, a modo de lamelas o pliegues, uno parietal, lameloso y prominente, otro lameloso columelar y tres pliegues palatales de distintos tamaños y direcciones, labro reflejado, formando un reborde estrecho, callo parietal fuerte, la teleoconcha lleva líneas de crecimiento a modo de fina estriación axial, protoconcha lisa, color blanco.

Dimensiones del material ilustrado (MACN-Pi 4738): alt: $2,8 \mathrm{x} \mathrm{dm}: 1,2 \mathrm{~mm}$.

Localidad tipo: Bolivia, La Laguna, Pampa Ruiz, en las últimas colinas de la cuesta oriental de los Andes.

Distribución geográfica: Perú, Bolivia. En Argentina ocupa el norte y centro del país.

Distribución estratigráfica: Holoceno tardío - Reciente. Hábitat y requerimientos ecológicos: Terrestre, geófila, en regiones templadas y tropicales; en cobertura vegetal y debajo de rocas, maderas, musgos y hojas.

Material tipo: No ubicado.

Repositorios: DCG-MLP-007-810. Villa Valle María (nivel inferior), Diamante, Entre Ríos; $2.490 \pm 45$ A.P. 25 ejs.; DCG-MLP-007-817. Villa Valle María (nivel medio), Diamante, Entre Ríos; $2.490 \pm 45$ A.P. 51 ejs.; DCGMLP-007-825. Villa Valle María (nivel superior), Diamante, Entre Ríos; $2.490 \pm 45$ A.P. 18 ejs.; MACN-Pi 4.738. Bajada del balneario de Aldea Valle María, Diamante, Entre Ríos. Col. E. Tonni, 2000. 22 ejs. Holoceno; MAS PALEOINV 267. Villa Valle María (nivel inferior), Diamante, Entre Ríos; $2.490 \pm 45$ A.P. 1 ej.

Registro en el Cuaternario de Argentina: Holoceno tardío (Entre Ríos: Diamante).

Superfamilia Succineoidea Beck, 1837 Familia Succineidae Beck, 1837

\section{Succinea Draparnaud, 1801}

Especie tipo: Helix amphibia Draparnaud, 1801.

Sinónimos: Véase Zilch (1959-60).
Distribución estratigráfica: Paleoceno - Reciente (Zilch, 1959-60).

Distribución estratigráfica en Argentina: Ensenadense - Reciente (Frenguelli, 1957); según Doering (1884c: 22) presente desde el Terciario.

\section{Succinea meridionalis d'Orbigny, 1846}

Fig. 3

1837. Succinea oblonga d'Orb.: 231.

*1846. Succinea meridionalis (d'Orb.); d'Orb.: 711.

1907. Succinea meridionalis (d'Orb.); Doering: 177.

v1957. Succinea meridionalis (d'Orb.); Frenguelli: 58; 90.

1967. Succinea meridionalis (d'Orb.); Camacho: 152, lám. 18, figs. 7a, b.

2004. Succinea meridionalis (d'Orb.); Prieto et al.: 150, fig. $3 a$.

v2007. Succinea meridionalis (d'Orb.); De Francesco et al.: 464, lám. 3, fig. C.

v2011. Succinea meridionalis (d'Orb.); Aguirre et al.: 8, fig. 4 (4).

Descripción: Concha delgada, mediana, oval - alargada; de 3 1/2 vueltas convexas, la última ocupa 3/4 del largo total; espira breve; imperforada, sutura profunda e inclinada; abertura oblonga, alargada, expandida anteriormente, que ocupa 2/3 del largo total; callo presente; peristoma entero, simple; labro delgado y frágil; superficie ornamentada sólo por líneas de crecimiento; color blanco amarillento.

Dimensiones del ejemplar ilustrado (MLP 5.887): 17,6 x 9,1 mm.

Localidad tipo: Río de la Plata (restringida por Parodiz, 1957).

Distribución geográfica: Perú, Brasil, Bolivia, Paraguay, Uruguay. En Argentina, en áreas tropicales y templadas hasta el norte de la Patagonia (Hylton Scott, 1963). Con dudas para Chile (Stuardo \& Vega, 1985).

Distribución estratigráfica: Pleistoceno temprano - Reciente (Doering, 1884b,c; Frenguelli, 1957; De Francesco et al., 2007).

Hábitat y requerimientos ecológicos: Terrestre, de preferencia higrófila de agua dulce, puede habitar variedad de ambientes, v.g., terrenos muy húmedos inundados por agua de lluvias, bajo piedras al borde de cuerpos de agua lóticos y lénticos e, inclusive, con importantes niveles de salinidad (pantanos costeros marinos) (d'Orbigny, 1837: 232; Castellanos \& Landoni, 1995; De Francesco et al., 2007). Material tipo: NHM (Col. d'Orbigny como S. oblonga). Repositorios: DCG-MLP-007-818. Villa Valle María (nivel medio), Diamante, Entre Ríos; $2.490 \pm 45$ A.P. 1 ej. MACN-Pi 4.867. Arroyo La Estacada, valle de Uco, Mendoza. Pleistoceno tardío. 5 ejs. MLP 1.273. Arroyo del Durazno, Miramar, Buenos Aires. Col. J.F., 27 ejs. Platense. MLP 1.274. Luján, Buenos Aires. Col. J.F., 60 ejs. Platense. MLP 1.275. Aguaducho del Puente Hablador, Córdoba. Col. J.F., 32 ejs. Platense. MLP 1.276. Punta 
Hermengo, Miramar, Buenos Aires. Col. J.F., 14-I-1923. 100 ejs. Aimarense (médanos). MLP 1.277. Quilino (Trípoli), Córdoba. Col. J.F., 45 ejs. Platense. MLP 1.278. Altos de San Vicente, Córdoba. Col. J.F., 13 ejs. Cordobense. MLP 1.286. Altos de San Vicente, Córdoba. Col. J.F., 140 ejs. Platense y Cordobense. MLP 1.287. Quequén Salado, Puente de Oriente, Buenos Aires. Col. J.F., 147 ejs. Lujanense (parte inferior). MLP 1.288. Miramar, Buenos Aires. Col. J.F., 177 ejs. Aimarense. MLP 1.290. Ramal a Río Cuarto, Altos de San Vicente, Córdoba. Col. J.F., 25 ejs. Platense. MLP 1.309. Altos de San Vicente, Córdoba. Col. J.F., 1 ej. Cordobense. MLP 1.330. Mar Chiquita, borde sur, cerca de la boca del Saladillo. Col. J.F., 17IV-1930. 1 ej. Lujanense. MLP 3.798. Barrancas del Golf, Miramar, Buenos Aires. Col. J.F., 1 ej. Ensenadense. MLP 5.860. La Dulce, barrancas del Quequén Grande, Buenos Aires. Col. J.F., 18 ejs. Lujanense. MLP 5.874. Malacara, Buenos Aires. Col. J.F., 3 ejs. Platense. MLP 5.875. Miramar, rambla, Buenos Aires. Col. J.F., 1 ej. Prebelgranense. MLP 5.876. Nueva Córdoba, Capital, Córdoba. Col. J.F., 1 ej. Cordobense, capa d. MLP 5.877. Arroyo Antoñico, Paraná, Entre Ríos. Col. J.F., 2 ejs. Prebonaerense. MLP 5.879. Arroyo Durazno, Miramar, Buenos Aires. Col. J.F., 1 ej. Platense. MLP 5.880. Bajada Pucará, Capital, Córdoba. Col. J.F., 11 ejs. Cordobense. MLP 5.882. Bajada del Carmelo, San Vicente, Córdoba. Col. J.F., 2 ejs. Cordobense. MLP 5.884. Camino de Miramar a Cancha de Golf, nacimiento cañas. Col. J.F., 11 ejs. Platense. MLP 5.885. Punta Hermengo, Miramar, Buenos Aires. Col. J.F., 13 ejs. Aimarense (médanos). MLP 5.886. Ramal a Río Cuarto, Córdoba. Col. J.F., 2 ejs. Tehuelchense. MLP 5.887. Colonia Lola, San José, Córdoba. Col. J.F., 6 ejs. Preplatense. MLP 5.888. Colonia Lola, San José, Córdoba. Col. J.F., 4 ejs. Precordobense. MLP 5.889. Colonia Videla, arroyo Calchín, Córdoba. Col. J.F., 9 ejs. Cordobense. MLP 5.890. Carhué, Alsina, Buenos Aires. Col. J.F., 21 ejs. Post-pampeano. MLP 7.432. Arroyo La Carolina, Mar del Sur, Buenos Aires. Col. J.F., 8 ejs. Platense.

Registros en el Cuaternario de Argentina: Pleistoceno y Holoceno. Ensenadense (Buenos Aires: Miramar); Bonaerense (Buenos Aires: Malacara, Miramar; Córdoba [Capital]; Entre Ríos: Paraná); Lujanense (Buenos Aires: Mar Chiquita, Quequén Grande, Quequén Salado); Platense (Buenos Aires: Luján, Mar del Sur, Miramar); Córdoba (Colonia Lola, Colonia Videla, Capital, Quilino, Río Cuarto, San Vicente, Puente Hablador); Pleistoceno tardío (Mendoza: valle de Uco); Holoceno (Buenos Aires: Alsina); Holoceno tardío (Entre Ríos: Diamante).

Observaciones: El lote MLP 5.878 (Trapal-Có, Río Negro. Col. J.F., 22-II-1930. 1 ej. Rionegrense) indica la existencia de esta especie desde el Terciario. La subespecie Succinea labiosa cornea Döring, 1873 puede ser un sinónimo de la forma nominotípica. El lote MLP 3.798 contiene un ejemplar del gasterópodo de agua dulce Lymnaea viator (d'Orb., 1835).

\section{Succinea rosariensis Döring, 1873}

Fig. 4

*1873. Succinea rosariensis Döring: 63, T. 2, figs. 20-23.

1874. Succinea rosarinensis (Döring); Doering: 75.

1877. Succinea rosarinensis (Doering); Doering: 227.

1884c. Succinea rosarinensis (Doering); Doering: 22.

1907. Succinea rosarinensis (Doering); Doering: 177.

Descripción: Concha poco sólida, oblonga, con $3-4$ vueltas convexas, espira aguda, abertura oblonga, ovada (Doering, 1874).

Dimensiones del ejemplar figurado: $11,5 \times 6,0 \mathrm{~mm}$ (Doering, 1874).

Distribución geográfica: Argentina: Buenos Aires (Carhué), Córdoba (Santa María), Mendoza (San Carlos), Santa Fe (Rosario).

Distribución estratigráfica: Terciario - Reciente.

Hábitat y requerimientos ecológicos: Vive debajo de los matorrales, entre el follaje del suelo, en áreas sombrías y húmedas, entre la hierba, en las barrancas de arroyos (Doering, 1874, 1881).

Repositorio: No existe.

Registro en el Cuaternario de Argentina: Pleistoceno superior: Córdoba (Santa María).

Observación: Especie que, sin material tipo ni identificado por el autor, resulta muy difícil de determinar.

\section{Succinea sp.}

1990. Succinea sp. Cuezzo: 201, lám. 2, fig. 4.

Descripción: Concha oval-oblonga, con gran desarrollo de la última vuelta, que ocupa $2 / 3$ del largo total, espira aguda, abertura oval.

Dimensiones: no consignadas.

Distribución geográfica: Argentina: Tucumán (Tafí Viejo). Distribución estratigráfica: Pleistoceno.

Repositorio: PIL 13511. Tafí Viejo, Tucumán. Pleistoceno: ? Lujanense. 1 ej.

Registro en el Cuaternario de Argentina: ? Lujanense (Tucumán: Tafí Viejo).

Superfamilia Punctoidea Morse, 1864

Familia Charopidae Hutton, 1884

\section{Radiodiscus Pilsbry \& Ferriss, 1906}

Especie tipo: R. millecostatus Pilsbry \& Ferriss 1906.

Sinónimos: ? Retidiscus Fonseca \& Thomé, 1995.

Distribución estratigráfica: ? Cretácico temprano de Argentina (Morton, 1999). Eoceno medio-tardío - Reciente (Miquel \& Bellosi, 2007; 2010).

Distribución estratigráfica en Argentina: ? Cretácico 
temprano de Argentina (Morton, 1999). Eoceno mediotardío - Reciente (Miquel \& Bellosi, 2007, 2010).

\section{Radiodiscus quillajicola Vargas-Almonacid, 2000}

Fig. 5

*2000. Radiodiscus quillajicola Vargas-Almonacid: 62, lám.1, figs. 1-4; lám. 2, figs. 1-2.

v2007. Radiodiscus sp. aff. Radiodiscus quillajicola (VargasAlmonacid); De Francesco et al.: 465, fig. 3 D.

Descripción: Concha pequeña, discoidal, de 5 1/2 vueltas, espira algo desarrollada, abertura amplia subcircular, ombligo grande (1/4 del diámetro mayor) y sutura marcada; teleoconcha con $33 / 4$ vueltas convexas, llevando 90 costillas axiales en la última, entre las que aparecen diminutas cóstulas axiales; protoconcha con $13 / 4$ vueltas y alrededor de 17 cóstulas espirales, cruzadas por estrías axiales tenues en su mitad final; color castañoamarillento.

Dimensiones del material ilustrado (MACN-Pi 4.864): $1,8 \times 1,0 \mathrm{~mm}$.

Localidad tipo: Chile, VII Región (Región del Maule), bosque esclerófito relictual conformado principalmente

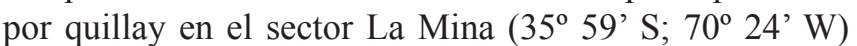
a $925 \mathrm{msnm}$, distante aproximadamente $10 \mathrm{~km}$ del Paso Internacional Pehuenche.

Distribución geográfica: Chile. Argentina: Mendoza.

Distribución estratigráfica: Pleistoceno tardío - Reciente. Hábitat y requerimientos ecológicos: Integrante de la fauna de suelo. En hojarasca de bosque esclerófito.

Material tipo: Radiodiscus quillajicola: Holotipo: UCCC 25501; Paratipos: UCCC 25512.

Repositorio: MACN-Pi 4.864. Arroyo La Estacada, valle de Uco, Mendoza. Pleistoceno tardío. 29 ejs.

Registro en el Cuaternario de Argentina: Pleistoceno tardío (Mendoza: valle de Uco).

Observación: Señalada como Radiodiscus sp. aff. Radiodiscus quillajicola por De Francesco et al. (2007).

\section{Retidiscus Fonseca \& Thomé, 1995}

Especie tipo: Retidiscus reticulatus Fonseca \& Thomé, 1995.

Sinónimo: ? Radiodiscus Pilsbry \& Ferriss, 1906.

Distribución estratigráfica: Holoceno medio - Reciente (Miquel \& Steffan, 2005).

Distribución estratigráfica en Argentina: Holoceno medio - Reciente (Miquel \& Steffan, 2005).

Retidiscus reticulatus Fonseca \& Thomé, 1995 Fig. 6
*1995. Retidiscus reticulatus Fonseca \& Thomé: 57, figs. 1-6. v2005. Retidiscus reticulatus (Fonseca \& Thomé); Miquel \& Steffan: 495, figs. 2.A-D.

Descripción: Concha pequeña, discoide, de espira moderada, 4 1/4 vueltas convexas de crecimiento regular, abertura subcircular, ombligo grande y perspectivo (1/4 del tamaño del diámetro mayor), sutura impresa y callo marcado; teleoconcha con 120 costillas radiales en la última vuelta; protoconcha con 20 cóstulas espirales e incisuras axiales; color del perióstraco castaño-amarillento.

Dimensiones del ejemplar ilustrado (MACN-Pi 4.717): $1,7 \times 0,9 \mathrm{~mm}$.

Localidad tipo: Brasil, Rio Grande do Sul, Viamão, Parque Saint-Hilaire.

Distribución geográfica: Brasil. Argentina (Buenos Aires). Distribución estratigráfica: Holoceno medio - Reciente. Hábitat y requerimientos ecológicos: Habita en el humus y la hojarasca, y entre raicillas, con relativa humedad. Material tipo: MCNZ 33487a (no hallado); MCNZ 33487 b (no hallado).

Repositorios: FSC-IN-RQG-2. Río Quequén Grande, Lobería, Buenos Aires. Leg. P. Steffan. 19 ejs., Holoceno medio; MACN-Pi 4.717. Río Quequén Grande, Lobería, Buenos Aires. Leg. P. Steffan. 2 ejs. Holoceno medio. Registros en el Cuaternario de Argentina: Holoceno tardío (Buenos Aires: Lobería).

Observación: El género Reticulatus podría ser un sinónimo junior de Radiodiscus (Miquel \& Cádiz Lorca, 2009).

\section{Rotadiscus Pilsbry, 1926}

Especie tipo: Helix hermanni Pfeiffer, 1866.

Distribución estratigráfica: Eoceno medio-tardío - Reciente (Miquel \& Bellosi, 2007, 2010).

Distribución estratigráfica en Argentina: Eoceno mediotardío - Reciente (Miquel \& Bellosi, 2007, 2010).

\section{Rotadiscus amancaezensis (Hidalgo, 1869)}

Fig. 7

*1869. Helix amancaezensis Hidalgo: 411

1870. Helix amancaezensis (Hidalgo); Hidalgo: 38, pl. 6, fig. 3.

*1927. Endodonta discoidea Thiele: 323, Taf. 26, fig. 26.

*1948. Stephanoda jujuyensis Hylton Scott: 251, fig. 4.

v2007. Rotadiscus amancaezensis (Hidalgo); De Francesco et al.: 465, fig. 3 E.

v2007. Rotadiscus amancaezensis (Hidalgo); Miquel et al.: 211, figs. 7, 8 y 9 .

Descripción: Concha pequeña, discoidal, de espira muy baja, que apenas sobrepasa a la última vuelta, con 5 - 5 $1 / 2$ vueltas convexas de crecimiento lento, abertura semilunada, no dilatada, con peristoma liso y cortante, ombligo abierto, perspectivo, que alcanza $1 / 3$ del diámetro máxi- 
mo; teleoconcha con costulación radial regular y conspicua, entre las que aparecen cóstulas muy tenues paralelas; protoconcha lisa, de $13 / 4$ vueltas casi planas; color castaño claro con tonos rojizos.

Observación: De acuerdo a Weyrauch (1965), en el interior de algunos ejemplares aparece un pliegue palatal bajo y largo, blanquecino, calloso, falciforme, con los extremos $\mathrm{y}$ el borde libre rómbicos y redondeados, que se localiza a 1/5 de la abertura, extendiéndose desde la base hasta la periferia de la vuelta del cuerpo.

Dimensiones del material ilustrado (MACN-Pi 4.863): $2,5 \times 1,3 \mathrm{~mm}$.

Localidad tipo: Perú: Amancaes.

Distribución geográfica: Perú, Bolivia, Brasil, centrosur de Chile, norte y centro de Argentina, hasta el norte de la Patagonia.

Distribución estratigráfica: Pleistoceno tardío - Reciente. Hábitat y requerimientos ecológicos: Habita en el humus y la hojarasca, y entre raicillas, con relativa humedad, y a la sombra de matorrales.

Material tipo: Sintipos (4): MNHN 5140.

Repositorios: MACN-Pi 4.863. Arroyo La Estacada, valle de Uco, Mendoza. Pleistoceno tardío. 1 ej.

Registros en el Cuaternario de Argentina: Pleistoceno tardío (Mendoza: valle de Uco).

Superfamilia Achatinoidea Swainson, 1840

Familia Ferussaciidae Bourguignat, 1883

\section{Cecilioides Férussac, 1814}

Especie tipo: Bulimus acicula Müller, 1774.

Sinónimos: Véase Zilch, 1959-60: 338.

Distribución estratigráfica: Mioceno - Reciente (Zilch, 1959-60).

Distribución estratigráfica en Argentina: Holoceno tardío - Reciente (Tonni et al., 2001; Aguirre et al., 2011).

\section{Cecilioides consobrina (d'Orbigny, 1837)} Fig. 8

*1837. Achatina consobrina d'Orb.: 89, pl. 11 (bis), figs. 10-12. 1948. Cecilioides (Caecilianopsis) consobrina (d'Orb.); Hylton Scott: 254.

v2001. Cecilioides consobrina (d'Orb.); Tonni et al. 2.

v2011. Cecilioides consobrina (d'Orb.); Aguirre et al. 10, fig. $4(5)$.

Descripción: Concha pequeña, oval - alargada, con 4 1/4 vueltas poco convexas, la última ocupa $50 \%$ del largo total, suturas apenas marcadas, abertura alargada e inclinada, de alrededor de 1/3 del largo total, labro delgado; teleoconcha con líneas de crecimiento; protoconcha lisa; color blanco brillante.
Dimensiones del material ilustrado (DCG-MLP-007-811): $2,0 \times 0,7 \mathrm{~mm}$.

Localidad tipo: Cerca de Matanzas, Cuba.

Distribución geográfica: Caribe y América del Sur. En Argentina ocupa el norte y centro del país y Mesopotamia. Distribución estratigráfica: Holoceno tardío - Reciente. Hábitat y requerimientos ecológicos: Terrestre, geófila, entre restos vegetales y debajo de troncos, en áreas templadas y tropicales. Género con especies de hábitos hipógeos (Heller et al., 1991).

Material tipo: NHM no. 1854.10.4.56. Sintipos.

Repositorios: DCG-MLP-007-811. Villa Valle María (nivel inferior), Diamante, Entre Ríos; $2.490 \pm 45$ A.P. 3 ejs.; DCG-MLP-007-819. Villa Valle María (nivel medio), Diamante, Entre Ríos; $2.490 \pm 45$ A.P. 1 ej.; MACN-Pi 4.740. Holoceno. Bajada del balneario de Aldea Valle María, Diamante, Entre Ríos. Col. E. Tonni, 2000. 3 ejs.; MAS PALEOINV 268. Villa Valle María (nivel inferior), Diamante, Entre Ríos; $2.490 \pm 45$ A.P. 1 ej.

Registro en el Cuaternario de Argentina: Holoceno tardío (Entre Ríos: Diamante).

Superfamilia Strophocheiloidea Pilsbry, 1902

Familia Strophocheilidae Pilsbry, 1902

\section{Austroborus Parodiz, 1949}

Especie tipo: Bulimus lutescens King \& Broderip, 1831.

Sinónimos: Microborus Pilsbry, 1926a.

Distribución estratigráfica: ? Eoceno - Reciente (Miquel \& Bellosi, 2010).

Distribución estratigráfica en Argentina: ? Eoceno Reciente (Miquel \& Bellosi, 2010).

Observaciones: En relación con la nomenclatura de nivel familiar, aquí se sigue el criterio de Miquel \& Manceñido (1999).

\section{Austroborus cordillerae (Doering, 1877)}

Fig. 9

\footnotetext{
*1877. Bulimus (Borus) lutescens var. cordillerae Doering: 254.

*1918. Borus Rimanni Frenguelli: 228, fig. s/n.

*1918. Borus Rimanni var. fossilis Frenguelli: 228.

1923. Borus Rimanni (Frenguelli); Frenguelli: 406, figs. 1 y 2.

1948. Strophocheilus (Microborus) cordillerae (Doering); Bequaert: 174.

1971. Strophocheilus (Austroborus) cordillerae (Doering); Zilch: 197, T.11, fig. 3 .

1989. Austroborus cordillerae (Doering); Klappenbach \& Olazarri: 1, figs. 1 y 2.
}

Descripción: Concha ovada, de espira breve, con 4 1/2 vueltas convexas, última ventricosa, ombligo abierto y estrecho, abertura ovada-acuminada, peristoma reflejado y engrosado, sutura crenulada, primeras vueltas de la te- 

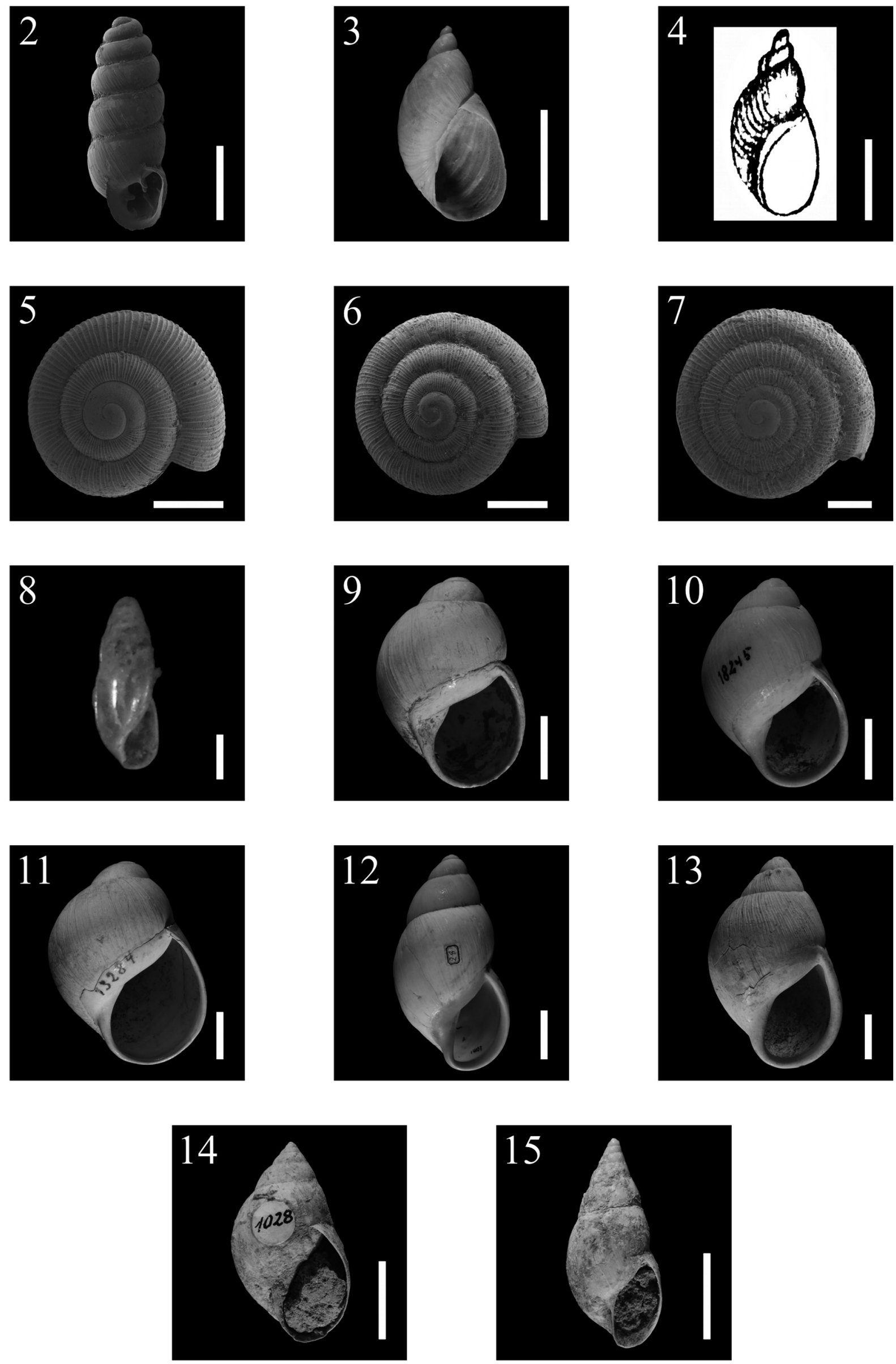
leoconcha con líneas axiales oblícuas, irregulares, cruzadas por otras espirales muy delicadas, que le otorgan un aspecto de retículo apretado, en la cuarta vuelta son sustituídas por costillas de crecimiento axiales gruesas; protoconcha de 2 vueltas lisas; color castaño claro.
Dimensiones del ejemplar ilustrado (MLP 10.524): 31,2 x $21,5 \mathrm{~mm}$.

Localidad tipo: Argentina: Córdoba, sierra de Achala (cerca de Córdoba).

Distribución geográfica: Argentina: oeste de Córdoba.

Figura 2. Gastrocopta nodosaria (d'Orbigny, 1835): MACN-Pi 4.738. Bajada del balneario de Aldea Valle María, Diamante, Entre Ríos. Holoceno. Escala: $1 \mathrm{~mm}$.

Gastrocopta nodosaria (d'Orbigny, 1835): MACN-Pi 4.738. Road downwards to balneario de Aldea Valle María, Diamante, Entre Ríos. Holocene. Scale: $1 \mathrm{~mm}$.

Figura 3. Succinea meridionalis d'Orbigny, 1846: MLP 5.887. Colonia Lola, San José, Córdoba. Preplatense. Escala: 10 mm. Succinea meridionalis d'Orbigny, 1846: MLP 5.887. Colonia Lola, San José, Córdoba. Preplatense. Scale: $10 \mathrm{~mm}$

Figura 4. Succinea rosariensis Döring, 1873: Fig. 22, tomada de A. Döring (1873). Escala: 5 mm. Succinea rosariensis Döring, 1873: Fig. 22, taken from A. Döring (1873). Scale: 5 mm.

Figura 5. Radiodiscus quillajicola Vargas-Almonacid, 2000: MACN-Pi 4.864. Arroyo La Estacada, valle de Uco, Mendoza. Pleistoceno tardío. Escala: 0,5 mm (modificado de De Francesco et al., 2007).

Radiodiscus quillajicola Vargas-Almonacid, 2000: MACN-Pi 4.864. La Estacada Creek, valle de Uco, Mendoza. Late Pleistocene. Scale: $0.5 \mathrm{~mm}$. (modified from De Francesco et al., 2007).

Figura 6. Retidiscus reticulatus Fonseca y Thomé, 1995: MACN-Pi 4.717. Río Quequén Grande, Lobería, Buenos Aires. Holoceno medio. Escala: 0,5 mm.

Retidiscus reticulatus Fonseca y Thomé, 1995: MACN-Pi 4.717. Quequén Grande river, Lobería, Buenos Aires. Middle Holocene. Scale: $0.5 \mathrm{~mm}$.

Figura 7. Rotadiscus amancaezensis (Hidalgo, 1869): MACN-Pi 4.863. Arroyo La Estacada, valle de Uco, Mendoza. Pleistoceno tardío. Escala: 0,5 mm. (modificado de De Francesco et al., 2007).

Rotadiscus amancaezensis (Hidalgo, 1869): MACN-Pi 4.863. Arroyo La Estacada, valle de Uco, Mendoza. Late Pleistocene. Scale: $0.5 \mathrm{~mm}$ (modified from De Francesco et al., 2007).

Figura 8. Cecilioides consobrina (d'Orbigny, 1837): DCG-MLP-007-811. Villa Valle María (nivel inferior), Diamante, Entre Ríos; $2.490 \pm 45$ A.P. Escala: $0,8 \mathrm{~mm}$.

Cecilioides consobrina (d'Orbigny, 1837): DCG-MLP-007-811. Villa Valle María (lower level), Diamante, Entre Ríos; $2.490 \pm 45$ A.P. Scale: $0.8 \mathrm{~mm}$.

Figura 9. Austroborus cordillerae (Doering, 1877): MLP 10.524. Pampa de Olaen, Córdoba. Actual. Escala: 10 mm. Austroborus cordillerae (Doering, 1877): MLP 10.524. Pampa de Olaen, Córdoba. Modern. Scale: $10 \mathrm{~mm}$.

Figura 10. Austroborus dorbignyi (Doering, 1877): MLP 18.245. Laguna Chasicó; Buenos Aires. Actual. Escala: 10 mm. Austroborus dorbignyi (Doering, 1877): MLP 18.245. Laguna Chasicó; Buenos Aires. Modern. Scale: $10 \mathrm{~mm}$.

Figura 11. Megalobulimus globosus (Martens in Pfeiffer, 1877): MLP 13.284. La Paz, Entre Ríos. Actual. Escala: 10 mm. Megalobulimus globosus (Martens in Pfeiffer, 1877): MLP 13.284. La Paz, Entre Ríos. Modern. Scale: $10 \mathrm{~mm}$.

Figura 12. Megalobulimus oblongus haematomus (Scopoli, 1786): MACN-In 14.007. Entre Ríos. Actual. Escala: 20 mm. Megalobulimus oblongus haematomus (Scopoli, 1786): MACN-In 14.007. Entre Ríos. Modern. Scale: 20 mm.

Figura 13. Megalobulimus oblongus lorentzianus (Doering, 1877): MLP 2.691. Isla Chica, Mar Chiquita, Córdoba. Platense. Escala: $20 \mathrm{~mm}$

Megalobulimus oblongus lorentzianus (Doering, 1877): MLP 2.691. Isla Chica, Mar Chiquita, Córdoba. Platense. Scale: $20 \mathrm{~mm}$.

Figura 14. Bulimulus apodemetes (d'Orbigny, 1835): MLP 1.028. Paraná, Entre Ríos. Cordobense. Escala: 10 mm. Bulimulus apodemetes (d'Orbigny, 1835): MLP 1.028. Paraná, Entre Ríos. Cordobense. Scale: $10 \mathrm{~mm}$.

Figura 15. Bulimulus bonariensis bonariensis (Rafinesque, 1833): MLP 1.028. Paraná, Entre Ríos. Cordobense. Escala: 10 mm. Bulimulus bonariensis bonariensis (Rafinesque, 1833): MLP 1.028. Paraná, Entre Ríos. Cordobense. Scale: $10 \mathrm{~mm}$. 
Distribución estratigráfica: Holoceno? - Reciente.

Hábitat y requerimientos ecológicos: Integrante de la fauna de suelo. No se conocen en detalle.

Material tipo: SMF 28743 (Zilch, 1971).

Repositorio: MLP 10.524. Pampa de Olaen, Córdoba. Col. A.R. González. 1 ej.

Registro en el Cuaternario de Argentina: ?Holoceno: Córdoba (oeste de la provincia).

Observación: Su sinónimo posterior Borus rimanni fue descripto como especie viviente, además de la subespecie ("variedad") fósil de la misma área, $B . r$ fossilis.

\section{Austroborus dorbignyi (Doering, 1877)}

Fig. 10

1832. Bulinus nucleus Sowerby: fig. 33.

*1877. Bulimus (Borus) d'orbignyi Doering: 255.

1881. Borus d'orbignyi (Doering); Doering: 64, lám. 1, fig. 4.

1948. Strophocheilus (Microborus) dorbignyi (Doering); Bequaert: 172 , pl. 12, fig. 4; pl. 32, figs. 6-7.

1957. Strophocheilus orbignyi (Doering); Frenguelli: 58.

1967. Strophocheilus (Megalobulimus) orbignyi (Doering); Camacho: 156.

1969. Strophocheilus (Austroborus) lutescens dorbignyi (Doering); Parodiz: 178, pl. 18, fig. 4.

1971. Strophocheilus (Austroborus) d'orbignyi (Doering); Zilch: 197, T. 11, fig. 4.

Descripción: Concha mediana, gruesa, ovada, rimada, de espira breve, ápice obtuso, 4 1/3 vueltas convexas, sutura somera, abertura oval, labro grueso, con acreciones en los ejemplares viejos; teleoconcha con gránulos gruesos e irregulares; protoconcha con costillas axiales muy irregulares, incompletas o quebradas y, a veces, sólo presentes por debajo de la sutura, combinada con la granulación espiral, origina una superficie vermiculada; color claro (Bequaert, 1948). Dimensiones del ejemplar ilustrado (MLP 18.245): 33,8 x 20,4 mm.

Localidad tipo: Valle de Sauce Chico, sudoeste de la provincia de Buenos Aires, Argentina (Parodiz, 1957).

Distribución geográfica: Argentina: sur de la provincia de Buenos Aires.

Distribución estratigráfica: Plioceno tardío - Reciente. Hábitat y requerimientos ecológicos: Integrante de la fauna de suelo. No se conocen en detalle.

Material tipo: Lectotipo: SMF 9511 (Zilch, 1971) (véase comentario de Parodiz,1969: 178).

Repositorio: MACN-In 18.245. Laguna Chasicó; Buenos Aires. Col. L. Kraglievich, XI-1928. 12 ejs.

Registros en el Cuaternario de Argentina: Pleistoceno y Holoceno. Ensenadense: Buenos Aires (Miramar); Bonaerense: Buenos Aires (Miramar); Platense: Buenos Aires (Bahía Blanca, Necochea, río Quequén Salado) (Camacho, 1966).

Observación: El estatus específico de esta entidad fue reconocido por Pilsbry (1926a) y mantenido por Bequaert (1948).

\section{Megalobulimus Miller, 1878}

Especie tipo: Borus garciamorenoi Miller, 1878.

Sinónimos: Véase Zilch (1959-60).

Distribución estratigráfica: Paleoceno - Reciente (Zilch, 1959-60).

Distribución estratigráfica en Argentina: Eoceno mediotardío (Miquel \& Bellosi, 2010).

\section{Megalobulimus globosus}

(Martens in Pfeiffer, 1877)

Fig. 11

*1877. Bulimus globosus Martens in Pfeiffer: 17.

1877. Bulimus (Borus) globosus (Martens in Pfeiffer); Martens: 24, pl. 140, figs. 2-3.

1948. Strophocheilus (Megalobulimus) globosus (Martens in Pfeiffer); Bequaert: 142, pl. 4, fig. 7; pl. 15, fig. 2; pl. 20, fig. 2.

1969. Strophocheilus globosus (Martens in Pfeiffer); Parodiz: 173.

Descripción: Concha de crecimiento regular, 4 2/3 vueltas convexas, ápice obtuso, redondeado, liso, labro poco expandido y moderadamente engrosado; protoconcha con costillas axiales bajas, regularmente espaciadas en las últimas vueltas embrionarias; perióstraco castaño-amarillento, brillante, con unas pocas bandas oscuras; labro y columela de color blanco (Bequaert, 1948).

Dimensiones del ejemplar ilustrado (MLP 13.284): 41,4 x $28,4 \mathrm{~mm}$.

Localidad tipo: Desconocida. Según Parodiz (1957), cerca de Montevideo, Uruguay.

Distribución geográfica: Brasil, Uruguay. En Argentina, se la encuentra viviente en la provincia de Entre Ríos.

Distribución estratigráfica: Pleistoceno - Reciente.

Hábitat y requerimientos ecológicos: Integrante de la fauna de suelo. No se conocen en detalle.

Material tipo: ZMB? (Bequaert, 1948).

Repositorio: MACN-In 13.284. La Paz, Entre Ríos. Col. P. Serié, VII-1922. MACN-In 26.575. Concepción del Uruguay, Entre Ríos. Col. E.A. Maury, IX-1963. 3 ejs.

Registros en el Cuaternario de Argentina: Pleistoceno: Buenos Aires; Entre Ríos (Parodiz, 1969: 175).

\section{Megalobulimus oblongus haematomus (Scopoli, 1786) Fig. 12}

*1786. Bulimus haemastomus Scopoli: 67, pl. 25, fig. B1, 2. 1884c. Bulimus oblongus var. crassa (Albers); Doering: 22. 1907. Borus crassus (Albers) Ihering: 464.

1948. Strophocheilus (Megalobulimus) haemastomus (Scopoli); Bequaert: 74, pl. 2, fig. 2; pl. 21, fig. 4; pl. 24, fig. 5. 
1969. Strophocheilus (Megalobulimus) oblongus haemastomus (Scopoli); Parodiz: 176.

Descripción: Concha sólida, eliptica, imperforada, 6,5 vueltas convexas, abertura grande, marginada, labro de color rojo, teleoconcha con costillas de crecimiento (Scopoli, 1786 fide Bequaert, 1948).

Dimensiones del ejemplar ilustrado (MACN-In 14.007): 83,3 x 40,9 mm.

Localidad tipo: Desconocida.

Distribución geográfica: Brasil, Paraguay, Uruguay. En Argentina, en la región chaqueño-pampeana y mesopotámica.

Distribución estratigráfica: ? Formación Paraná (Parodiz, 1969) (? Mioceno) - Reciente.

Hábitat y requerimientos ecológicos: Integrante de la fauna de suelo. No se conocen en detalle.

Material tipo: No localizado.

Repositorio: MACN-In 14.007. Entre Ríos. Col. A. Bravard. 80 ejs. MACN-In 30.530. Entre Ríos. Col. A. Doering, 1 ej.

Registros en el Cuaternario de Argentina: No están documentados, pero la especie tiene registros en el Néogeno (Parodíz, 1969).

\section{Megalobulimus oblongus lorentzianus}

(Doering, 1877)

Fig. 13

*1877. Bulimus (Borus) lorentzianus Doering: 225.

1878. Bulimus (Borus) lorentzianus (Doering); Doering: 336.

1923. Borus oblongus lorentzianus (Doering); Frenguelli: 7, fig. 3.

1948. Strophocheilus (Megalobulimus) oblongus lorentzianus (Doering); Bequaert: 80, pl. 27, fig. 5.

v1957. Strophocheilus lorentzianus (Doering); Frenguelli: 76; 78; 91; 92.

1971. Borus oblongus lorentzianus (Doering); Zilch: 197, T. 11, figs. 1-2.

1973. Strophocheilus (Megalobulimus) oblongus lorentzianus (Doering); Fernández: 66.

Descripción: Concha sólida, ovada, subimperforada, ápice obtuso, 6 vueltas convexas rápidamente acrescentes, última vuelta ocupa $60 \%$ del largo total, abertura oval-oblonga, oblicua, peristoma algo expandido, reflejado, que forma una orla de 3 ó $4 \mathrm{~mm}$, de color rojo brillante, callo espeso, liso y de contorno muy neto, cubriendo la perforación umbilical; teleoconcha con estrías paralelas longitudinales irregulares; protoconcha regularmente costulada, puede aparecer un finísimo puntillado entre las estrías rugosas, haciéndose más visible en las vueltas adultas jovenes, color blanco.

Dimensiones del ejemplar ilustrado (MLP 2.691): 85,0 x $50,0 \mathrm{~mm}$.

Localidad tipo: Sierras de Tucumán, Argentina.
Distribución geográfica: Bolivia. En Argentina, norte y región centro-oriental.

Distribución estratigráfica: Pleistoceno - Reciente.

Hábitat y requerimientos ecológicos: Integrante de la fauna de suelo. No se conocen en detalle. En períodos secos se entierran; los huevos calcáreos los depositan en habitáculos que construyen bajo la tierra.

Material tipo: Lectotipo: SMF 9512a; Paralectotipo: SMF 9512b (Zilch, 1971).

Repositorio: MLP 2.691. Isla Chica, Mar Chiquita, Córdoba. Col. J.F., 1930. 4 ejs. Platense.

Registros en el Cuaternario de Argentina: Pleistoceno. Bonaerense: Entre Ríos (Paraná); Platense (Córdoba: Capital, Mar Chiquita; Santiago del Estero: río Dulce).

\section{Superfamilia Orthalicoidea Albers-Martens, 1860 \\ Familia Orthalicidae Albers-Martens, 1860 \\ (= Bulimulidae Crosse \& Fischer, 1873) \\ Subfamilia Bulimulinae Tryon, 1867}

\section{Bulimulus Leach, 1814}

Especie tipo: Helix exilis Gmelin, 1791.

Sinónimos: ? Paleobulimulus Parodiz, 1949.

Distribución estratigráfica: Eoceno - Reciente (Simone \& Mezzalira, 1994; Genise et al., 2010).

Distribución estratigráfica en Argentina: Eoceno temprano - Reciente (Melchor et al., 2002; Genise et al., 2010).

\section{Bulimulus apodemetes (d'Orbigny, 1835)}

Fig. 14

*1835. Helix (Cochlogena) apodemeta d'Orbigny: 10.

1837. Bulimus apodemetes (d'Orb.); d'Orbigny: 279, pl. 30, figs. 5-8.

1897b. Bulimulus (Bostryx-Lissoacme) apodemtes (d'Orb.); Pilsbry: 187, pl. 51, figs. 1-4.

1946b. Bulimulus (Bulimulus) apodemtes (d'Orb.); Parodiz: 315, figs. 2,30, 38; lám. 2, fig. 1.

v1957. Bulimulus apodemetes (d'Orb.); Frenguelli: 75, 78, 91.

1991. Bulimulus apodemetes (d'Orb.); Miquel: 95, figs. 9-19, 45,46 y 59 .

2001. Bulimulus apodemetes (d'Orb.); Tonni et al:: 2.

v2011. Bulimulus apodemetes (d'Orb.); Aguirre et al.: 11, fig. 4 (9).

Descripción: Concha mediana, delgada, ventricosa, con ombligo notorio a ausente, 6 a $6 \frac{1}{2}$ vueltas convexas a subconvexas, la última ocupa entre $75 \%$ y $80 \%$ de la longitud total, espira escasa a muy escasa, con ápice obtuso, suturas irregulares y profundas, abertura oblicua de gran desarrollo, llegando a ocupar hasta 2/3 del largo total, peristoma simple, cortante, columela oblicua, callo ausente a notorio, teleoconcha con bandas axiales de crecimiento notorias muy irregulares y sobresalientes; protoconcha con 
microesculturación de bandas en zig-zag, separadas y de escasa angulosidad; color castaño claro con bandas cremas. Dimensiones del ejemplar ilustrado (MLP 1.028): 25,2 $\mathrm{x} 14,0 \mathrm{~mm}$.

Localidad tipo: Argentina, Santa Fe, San Lorenzo (Breure, 1976).

Distribución geográfica: Bolivia, Paraguay, Uruguay. En Argentina, norte y centro del país.

Distribución estratigráfica: Pleistoceno - Reciente.

Hábitat y requerimientos ecológicos: Terrestres, geófilos, en regiones templadas y tropicales.

Material tipo: MNHN Sintipos (Miquel, 1991).

Repositorios: DCG-MLP-007-813. Villa Valle María (nivel inferior), Diamante, Entre Ríos; $2.490 \pm 45$ A.P. 23 ej. MACN-In 17.776. Concepción, Catamarca. Leg. M. Gómez, III-1928. 130 ejs. MLP 1.028. Paraná, Entre Ríos. Col. J.F., 1 ej. Cordobense. MLP 1.029. Aguas Corrientes, Paraná, Entre Ríos. Col. J.F., 2 ejs. Bonaerense. MLP 1.031. Calera Aldasoro, Paraná, Entre Ríos. Col. J.F., 8 ejs. Bonaerense. MLP 1.032. Gral. Paz, entre el Hipódromo y el Hospital Italiano, Córdoba. Col. J.F., 3 ejs. Precordobense. MLP 1.038. Calera Aldasoro, Paraná, Entre Ríos. Col. J.F., 2 ejs. Bonaerense. MLP 1.041. Bajada del Carmelo, San Vicente, Córdoba. Col. J.F., 1 ej. Cordobense. MLP 1.042. Boca de la toma del canal San Martín, Santiago del Estero. Col. J.F., 17-VII-1929. 9 ejs. Bonaerense. MLP 1.043. Arroyo Calchín, Colonia Videla, Córdoba. Col. J.F., 11 ejs. Bonaerense. MLP 5.907. El Brete, Paraná, Entre Ríos. Col. J.F., 1 ej. Cordobense; MAS PALEOINV 270. Villa Valle María (nivel inferior), Diamante, Entre Ríos; $2.490 \pm 45$ A.P. 1 ej.

Registros en el Cuaternario de Argentina: Pleistoceno y Holoceno. Bonaerense (Córdoba: Colonia Videla; Entre Ríos: Paraná; Santiago del Estero: canal San Martín); ? Lujanense: Tucumán (Tafí Viejo); Platense (Córdoba: General Paz, San Vicente; Entre Ríos: Paraná, Santiago del Estero (río Dulce); Holoceno tardío (Entre Ríos: Diamante).

\section{Bulimulus bonariensis bonariensis} (Rafinesque, 1833)

Figs. 15 y 16

*1833. Syphalomphix bonariensis Rafinesque: 165.

p.1835. Helix (Cochlogena) sporadica d'Orbigny: 12.

p.1837. Bulimus sporadicus (d'Orb.); d'Orbigny: 271.

v1957. Bulimulus sporadicus (d'Orb.); Frenguelli: 75.

1962. Bulimulus bonariensis bonariensis (Raf.); Parodiz: 432.

1991. Bulimulus bonariensis bonariensis (Raf.); Miquel: 98, figs. 20-34, 48-51 y 60.

2001. Bulimulus bonariensis bonariensis (Raf.); Tonni et al.: 2.

2003. Bulimulus bonariensis bonariensis (Raf.); Prieto et al.: 151.

v2011. Bulimulus bonariensis bonariensis (Raf.); Aguirre et al.: 12, fig. 4 (10).
Descripción: Concha mediana a grande, suboval, con ombligo estrecho, 7 a 7 3/4 vueltas subconvexas, la última ocupa $70 \%$ de la longitud total, espira de desarrollo mediano, suturas poco profundas, la abertura puede ocupar $50 \%$ del largo total, siendo un poco oblicua, peristoma cortante no reflejado, con suave expansión, pared columelar reflejada, callo mal definido, la teleoconcha presenta bandas de crecimiento, a veces muy notorias, y está recorrida por surcos espirales muy tenues e irregulares; protoconcha con microescultura de bandas en zig-zag apretadas; color verde claro.

Dimensiones del ejemplar ilustrado (MLP 1.028): 24,1 $\mathrm{x} 10,5 \mathrm{~mm}$.

Localidad tipo: Argentina, Buenos Aires.

Distribución geográfica: Uruguay. En Argentina, en la región chaqueño-pampeana y mesopotámica.

Distribución estratigráfica: Pleistoceno - Reciente.

Hábitat y requerimientos ecológicos: En cubierta vegetal, adheridos a la parte basal de arbustos y árboles, y de instalaciones humanas (alambrados, paredes, etc.), en particular, a la sombra, en lugares húmedos.

Material tipo: No localizado.

Repositorios: DCG-MLP-007-814. Villa Valle María (nivel inferior), Diamante, Entre Ríos; $2.490 \pm 45$ A.P. 1 ej.; MACN-In 6.433. Orillas de río Paraná, San Nicolás, Buenos Aires. Leg. Scasso, 1945. 400 ejs. MLP 1.027. Borde izquierdo del río Salado, Estancia Nicanor Molina, Colonia Videla, Santa Fe. Col. J.F., 12-V-1929. 1 ej. frag. Platense. MLP 1.028. Paraná, Entre Ríos. Cordobense. Col. J.F., 2 ejs. MLP 5.866. Calera Aldasoro, Paraná, Entre Ríos. Bonaerense. Col. J.F., 1 ej.; MLP 5.901. Isla Chica, Mar Chiquita, Córdoba. Col. J.F., 1 ej. Platense. MLP 5.906. Punta Mogotes, Mar del Plata, Buenos Aires. Col. J.F., 1 ej. Belgranense. MLP 9.230. Faro de Punta Porvenir, Mar del Plata, Buenos Aires. Col. J.F., 1 ej. Belgranense (médanos).

Registros en el Cuaternario de Argentina: Pleistoceno y Holoceno. Bonaerense (Buenos Aires: Mar del Plata; Entre Ríos: Paraná); Platense: Entre Ríos (Paraná), Sante Fe (Colonia Videla); Holoceno tardío (Entre Ríos: Diamante). Observaciones: Subespecie habitualmente citada como $B$. sporadicus (Camacho, 1967) (véase Miquel, 1991). Materiales procedentes de un afloramiento del arroyo Las Brusquitas (prov. de Buenos Aires) mostró una antigüedad de $36.130+/-620$ años (Prieto et al., 2003).

\section{Bulimulus bonariensis sporadicus (d'Orbigny, 1835) Fig. 17}

p. ${ }^{*}$ 1835. Helix (Cochlogena) sporadica d'Orbigny: 12.

p.1837. Bulimus sporadicus (d'Orb.); d'Orbigny: 271, pl. 32, fig. 13.

1946b. Bulimulus (Bulimulus) sporadicus (d'Orb.); Parodiz: 306, 315, fig. 37. 
v1957. Bulimulus sporadicus (d'Orb.); Frenguelli: 91.

1991. Bulimulus bonariensis sporadicus (d'Orb.); Miquel: 101, figs. 35-44, 52-54, 60.

Descripción: Concha mediana a grande, subfusiforme a fusiforme, con ombligo desarrollado a estrecho, 7 a 9 $1 / 2$ vueltas de crecimiento regular, la última llega a ocupar 2/3 del largo total, espira moderada a grande, suturas no muy profundas y regulares, abertura bien desarrollada, oblicua, que ocupa entre $40 \%$ y $50 \%$ del largo total, peristoma cortante, columela oblicua, con su pared reflejada sobre el ombligo, callo ausente o débilmente marcado; teleoconcha con bandas axiales, regulares y no muy notorias, y estrías espirales poco insinuadas o ausentes; protoconcha con bandas en zig-zag típicas; color castaño suave, con bandas axiales más oscuras.

Dimensiones del ejemplar ilustrado (MLP 5.902): 23,0 x $9,7 \mathrm{~mm}$.

Localidad tipo: Bolivia, Santa Cruz de la Sierra, provincia de Chiquitos.

Distribución geográfica: Brasil, Paraguay. En Argentina, regiones norte y centro-oeste.

Distribución estratigráfica: Holoceno - Reciente.

Hábitat y requerimientos ecológicos: Similares a la subespecie $B . b$. bonariensis.

Material tipo: MNHN Sintipos (Miquel, 1991).

Repositorio: MLP 1.039. Altos de San Vicente, Córdoba. Cordobense. Col. J.F., 1 ej. MLP 5.902. Bajada Pucará, Capital, Córdoba. Cordobense, Col. J.F., 3 ejs. MLP 5.903. Colonia Lola, San José, Córdoba. Cordobense. Col. J.F., 4 ejs. MLP 25.247. Altos de San Vicente, Córdoba. Cordobense. Col. J.F., 1 ej. fragm.

Registros en el Cuaternario de Argentina: Holoceno. Platense (Córdoba: Capital, Colonia Lola, San Vicente).

Observaciones: los registros de Buenos Aires y Entre Ríos [Pleistoceno - Holoceno: Buenos Aires (sur y sureste de la provincia); Pleistoceno: Entre Ríos] pueden corresponder a la subespecie $B$. bonariensis bonariensis.

\section{Bulimulus rushii Pilsbry, 1897}

Fig. 18

1896. Bulimulus rushii Pilsbry \& Rush: 78.

*1897a. Bulimulus rushii Pilsbry: 18.

1897b. Bulimulus (Bulimulus) rushii (Pilsbry); Pilsbry: 70, pl. 12, fig. 47.

1946b. Bulimulus (Bulimulus) rushii (Pilsbry); Parodiz: 303, lám. 1, fig. 3 .

v1957. Protoglyptus durus (Spix); Frenguelli: 76.

1991. Bulimulus rushii (Pilsbry); Miquel: 103, figs. 3-5, 5759.

Descripción: Concha de tamaño mediano, sólida, ovalglobosa, fuertemente umbilicada, de 6 a 7 vueltas moderadamente convexas, abarcando la última $3 / 4$ partes de la longitud total, espira corta a muy corta, cónica y con ápi- ce obtuso, suturas poco profundas y bien definidas, abertura amplia, oval, ligeramente oblicua, ocupando 55\% del largo total, peristoma simple, algo reflejado en ejemplares gerónticos, borde columelar dilatado, especialmente en el extremo superior, callo poco conspícuo, a veces mal definido; teleoconcha con bandas de crecimiento débiles y líneas espirales; protoconcha con líneas vericales en zigzag, aunque los ángulos que forman son poco agudos y se disponen de manera menos apretada que en otras especies; color blanco grisáceo.

Dimensiones del ejemplar ilustrado (MLP 1.044): 22,9 $\mathrm{x} 12,8 \mathrm{~mm}$.

Localidad tipo: Uruguay, Maldonado, Maldonado.

Distribución geográfica: Uruguay. En Argentina, viviente en la región mesopotámica; fósil en el norte-este de la provincia de Buenos Aires.

Distribución estratigráfica: Pleistoceno - Reciente.

Hábitat y requerimientos ecológicos: Vive en la carpeta herbácea.

Material tipo: Lectotipo ANSP 70382. 1 ej.

Repositorios: MACN-In 12.956. Alrededores de La Curtiembre, Entre Ríos. Leg. J. Frenguelli. 18 ejs. MLP 1.044. Arroyo de la Curtiembre, Entre Ríos. Col. J.F., 10 ejs. PreAimarense. MLP 8.262. Maldonado, Buenos Aires. Col. Museo, 3 ejs. Platense.

Registros en el Cuaternario de Argentina: Pleistoceno y Holoceno. Bonaerense: Entre Ríos (Paraná); Platense (Buenos Aires: Maldonado; Entre Ríos: arroyo de la Curtiembre).

Observaciones: Citado como Protoglyptus durus Spix, 1827 por Frenguelli (1957: 76).

\section{Discoleus Breure 1978}

Especie tipo: Eudioptus aguirrei Doering, 1884a.

Distribución estratigráfica: Pleistoceno - Reciente (Parodiz, 1969).

Distribución estratigráfica en Argentina: Pleistoceno Reciente (Parodiz, 1969).

\section{Discoleus ameghinoi (Ihering, 1908)} Figs. 19 y 20

*1908. Bulimulus ameghinoi Ihering: 430, fig. 1.

*1914. Bulimulus sporadicus pampa Ihering: 70.

1946b. Peronaeus (Lissoacme) ameghinoi (Ihering); Parodiz: 315, lám. 1, fig.2; lám. 2, fig. 2.

v1957. Bulimulus ameghinoi (Ihering); Frenguelli: 58.

1967. Peronaeus (Lissoacme) ameghinoi (Ihering); Camacho: 148, lám. 17, fig. 16.

1969. “Bulimulus” ameghinoi (Ihering); Parodiz: 213.

1979. Discoleus ameghinoi (Ihering); Breure: 91.

1996. Bulimulus ameghinoi (Ihering); Parodiz: 199.

1998. Discoleus ameghinoi (Ihering); Miquel: 181, figs. 1, 2, $4,17,19$. 
Descripción: Concha de tamaño mediano, subovoide, rimada, de espira bien desarrollada, 6 vueltas subconvexas, la última ocupa $75 \%$ del largo total, abertura amplia, que ocupa más de la mitad de la longitud total, labro grueso, no reflejado, describiendo una suave y no muy pronunciada curva, callo bien marcado; teleoconcha con marcadas líneas de crecimiento; protoconcha con líneas espirales tenues; color castaño suave con bandas más oscuras. Dimensiones del ejemplar ilustrado (MACN-Pi 562): $22,7 \times 11,4 \mathrm{~mm}$.

Localidad tipo: Argentina, provincia de Buenos Aires, Gral. Pueyrredón, bancos del arroyo Chapadmalal.

Distribución geográfica: Argentina. Fósil en la provincia de Buenos Aires, viviente en las provincias de Chubut, Río Negro y Santa Cruz.

Distribución estratigráfica: Pleistoceno - Reciente.

Hábitat y requerimientos ecológicos: Integrante de la fauna de suelo. No se conocen en detalle.

Material tipo: Bulimulus ameghinoi: Holotipo; Bulimulus sporadicus pampa: 3 sintipos.

Repositorios: Bulimulus ameghinoi: MACN-Pi 562a. Holotipo; Bulimulus sporadicus pampa: MACN 562b,c,d. Sintipos (3). Buenos Aires. Pampeano inferior. Col. H. von Ihering. 3 ejs. MACN-In 18.445. Bahía Sanguinetto, Santa Cruz. Col. J. Frenguelli, IV-1929. 75 ejs. MLP 1.030. Punta Hermengo, Miramar, Buenos Aires. Col. J.F., 9-I-1932. 2 ejs. Lujanense. MLP 3.797. Punta Hermengo, Miramar, Buenos Aires. Col. Museo. Leg. J.F., 2-XI-1940. 1 ej. Lujanense. MLP 3.949. Arroyo Verde, Río Negro. Col. Museo. Leg. J.F., 10-III-1940. 2 ejs. Reciente. MLP 4.059. Arroyo Verde, Río Negro. Col. Museo. Leg. J.F., 10-III-1940. 11 ejs. Viviente. MLP 5.061. Punta Hermengo, Miramar, Buenos Aires. Col. Museo, leg. J.F. 7 ejs. Lujanense. MLP 5.064. Puerto de Quequén. Col. Museo. Leg. J.F. 1 ej. Postplatense-Cordobense. MLP 5.404. Boca del arroyo Durazno, Miramar, Buenos Aires. Col. J.F., 4-II-1937. 1 ej. Platense (base) y Querandinense (cúspide). MLP 5.851. Boca del arroyo Durazno, Miramar, Buenos Aires. Col. J.F., 6 ejs. (s/ edad). MLP 5.860. La Dulce, barrancas del río Quequén Grande, Buenos Aires. Col. J.F. 19 ejs.. Lujanense. MLP 5.883. Las Rocas, Miramar, Buenos Aires. Col. J.F.,39 ejs. Bonaerense o Platense? MLP 5.909. Desembocadura del arroyo Chocorí, Buenos Aires. Col. J.F. 2 ejs. Prebonaerense? MLP 8.363. Bahía Blanca, Buenos Aires. Col. Museo. 1 ej. Pampeano.

Registros en el Cuaternario de Argentina: Pleistoceno y Holoceno. Ensenadense: Buenos Aires (Miramar); ? Bonaerense (Buenos Aires: Miramar, arroyo Chocorí); Lujanense (Buenos Aires: Bahía Blanca, Miramar, río Quequén Grande); Platense (Buenos Aires: Miramar, Quequén).

\section{Naesiotus Albers, 1850}

Especie tipo: Bulinus nux Broderip, 1832.
Sinónimos: Véase Breure (1979).

Distribución estratigráfica: Holoceno tardío - Reciente (Aguirre et al., 2011).

Distribución estratigráfica en Argentina: Holoceno tardío - Reciente (Aguirre et al., 2011).

\section{Naesiotus deletangi (Parodiz, 1946)}

Fig. 21

*1946a. Protoglyptus deletangi Parodiz: 3, fig. 1; lám. 1, fig. 4. 1946b. Protoglyptus (Rimatula) deletangi (Parodiz); Parodiz: 315, fig. 43, lám. 1, fig. 6 .

1978. Naesiotus deletangi (Parodiz); Breure \& Coppois: tab. 2. 1989. Naesiotus deletangi (Parodiz); Miquel: 65, figs. 4, 5, 6, 23,25 y 27.

v2011. Naesiotus deletangi (Parodiz); Aguirre et al.: 13, figs. $4(16,17)$ y $5(4-8)$.

Descripción: Concha turritelada, de espira muy desarrollada, subumbilicada, con 9 vueltas convexas, las 5 primeras de crecimiento más lento y regular, las posteriores presentan casi el mismo diámetro, la última vuelta es alargada y apenas algo más ensanchada que las anteriores, ocupando la mitad de la longitud total, suturas profundas, abertura estrecha, ocupa 1/3 del largo total, lleva labro cortante, no reflejado, el que describe una línea recta o una suave curvatura, columela arqueada, cuya pared tapa al pequeño ombligo, callo no marcado o apenas insinuado; teleoconcha con marcadas líneas de crecimiento; protoconcha con escultura de costillas axiales paralelas, conspícuas, entre las cuales aparecen pequeñas costillas espirales; color castaño con bandas más oscuras. Dimensiones del ejemplar ilustrado (DCG-MLP-007822): $15,8 \times 7,4 \mathrm{~mm}$.

Localidad tipo: Argentina, Salta, Gral. J. de San Martín, Embarcación.

Distribución geográfica: Argentina. En forma disyunta, aparece registrado en el nor-oeste de Argentina y centrooeste de la provincia de Entre Ríos.

Distribución estratigráfica: Holoceno tardío - Reciente. Hábitat y requerimientos ecológicos: Integrante de la fauna de suelo. No se conocen en detalle.

Material tipo: Protoglyptus deletangi: Holotipo: MACNIn 3.131; Paratipos (17): MACN-In 3.131-1 (Tablado \& Mantinian, 2004).

Repositorio: DCG-MLP-007-822. Villa Valle María (nivel medio), Diamante, Entre Ríos; $2.490 \pm 45$ A.P. 4 ejs. MAS PALEOINV 272. Villa Valle María (nivel inferior), Diamante, Entre Ríos; $2.490 \pm 45$ A.P. 1 ej.

Registros en el Cuaternario de Argentina: Holoceno tardío (Entre Ríos: Diamante).

\section{Naesiotus pollonerae (Ancey, 1897)} Figs. 22 y 23

*1897. Bulimulus pollonerae Ancey: 17, fig. 10.

1978. Naesiotus pollonerae (Ancey); Breure \& Coppois: 181, figs. 27-29. 
1989. Naesiotus pollonerae (Ancey); Miquel: 69, figs.17,18,19 y 27.

2001. Naesiotus pollonerae (Ancey); Tonni et al.: 2

v2010. Naesiotus pollonerae (Ancey); Aguirre et al.: 13, fig. 4 (14-15).

Descripción: Concha de tamaño mediano, subfusiforme, umbilicada, 8 vueltas convexas a subcovexas, suturas relativamente profundas e irregulares, todas las vueltas presentan un crecimiento regular, la última ocupa $60 \%$ del largo total, abertura amplia, oval, que ocupa $40 \%$ de la longitud total, labro cortante, no reflejado, columela inclinada, con pared que tapa al ombligo, callo generalmente marcado; teleoconcha con líneas de crecimiento bien marcadas, a veces, puede presentar una estructura martillada; protoconcha lleva costillas axiales, entre las que aparecen pequeñas cóstulas espirales; color castaño con bandas más oscuras. Dimensiones del ejemplar ilustrado (DCG-MLP-007821): $25,3 \times 12,8 \mathrm{~mm}$.

Localidad tipo: Bolivia, Santa Cruz, Cortadera.

Distribución geográfica: Bolivia, Uruguay. En Argentina, con distribución disyunta, en el noroeste del país y norte de la provincia de Buenos Aires.

Distribución estratigráfica: Holoceno tardío - Reciente. Hábitat y requerimientos ecológicos: Integrante de la fauna de suelo. No se conoce en detalle.

Material tipo: No localizado.

Repositorios: DCG-MLP-007-821. Villa Valle María (nivel medio), Diamante, Entre Ríos; $2.490 \pm 45$ A.P.; 5 ejs.; DCG-MLP-007-827. Villa Valle María (nivel superior), Diamante, Entre Ríos; $2.490 \pm 45$ A.P. 1 ej. MACN-In 6.435. Barrancas de San Nicolás, río Paraná, Buenos Aires. Leg. Scasso, V-1945. 3 ejs. MAS PALEOINV 271. Villa Valle María (nivel inferior), Diamante, Entre Ríos; $2.490 \pm 45$ A.P. 1 ej.

Registro en el Cuaternario de Argentina: Holoceno (Entre Ríos: Diamante).

\section{Subfamilia Odontostominae Pilsbry \& Vanatta in Pilsbry, 1898}

\section{Plagiodontes Doering, 1877}

Especie tipo: Helix dentata Wood, 1828.

Distribución estratigráfica: Eoceno temprano - Reciente (Melchor et al., 2002; Genise et al., 2010).

Distribución estratigráfica en Argentina: Eoceno temprano - Reciente (Melchor et al., 2002; Genise et al., 2010).

\section{Plagiodontes dentatus (Wood, 1828)}

Fig. 24

1821. Helix brasiliensis Fèrussac: no. 492.

1821. Helix Sowerbyana Fèrussac: 492 bis.
*1828. Helix dentata Wood: pl. 8, fig. 71.

1875a. Bulimus (Odontostomus) dentatus (Wood); Doering: 452. 1901-02. Odontostomus (Plagiodontes) dentatus (Wood); Pilsbry: 94, pl. 14, figs. 15-17; pl. 15, fig. 25.

1939. Odontostomus (Plagiodontes) dentatus (Wood); Parodiz: 715, lám. 1, fig. 9 .

1957. Plagiodontes dentatus (Wood); Frenguelli: 76.

1967. Cycodontina (Plagiodontes) dentatus (Wood); Camacho: 150, lám. 19, fig. 2.

1969. Cycodontina (Plagiodontes) dentata (Wood); Parodiz: 183, pl. 19, figs. 4-7.

2001. Plagiodontes dentatus (Wood); Tonni et al.: 2.

Descripción: Concha ovada, amplia y profundamente perforada, rimada, 6-8 vueltas convexas, espira de cerca de $15 \%$ de la longitud total, cónica, con ápice obtuso, abertura ovada subvertical, con 9 a 14 dientes (lamelas + pliegues), lamela parietal en forma de $\mathrm{L}$ o $\mathrm{C}$ entrando profundamente, la parte externa de este diente es más cuadrada y generalmente se une a un pequeño diente angular comprimido, 1 lamela columelar parcialmente vertical y separada es el diente más largo que ocluye la abertura, 1 pliegue basal en el límite entre el labio exterior (palatal) y el interior (columelar) es pequeño y agudamente comprimido, 1 a 3 (generamente 2) pliegues infrapalatales paralelos, iguales o subiguales en tamaño, a la derecha del pliegue basal, 1 lamela transversa bien desarrollada detrás de los pliegues infrapalatales, 1 lamela suprapalatal enteramente retorcida, en la mitad del labio externo, casi tan largo como la lamela columelar, 2 dientes suprapalatales conectados en su base, peristoma engrosado y estrechamente reflejado en los adultos; protoconcha con ondas estriadas, decusadas por líneas espirales en los ejemplares jóvenes; teleoconcha con líneas de crecimiento; color blanco.

Dimensiones del ejemplar ilustrado (MLP 1.307): 20,0 x $9,2 \mathrm{~mm}$.

Localidad tipo: Uruguay, cerro de Montevideo (Klappenbach \& Olazarri, 1973).

Distribución geográfica: Uruguay. En Argentina, Entre Ríos y nordeste de la provincia de Buenos Aires.

Distribución estratigráfica: Pleistoceno - Reciente. Mioceno del Uruguay (Parodiz, 1969: 183).

Hábitat y requerimientos ecológicos: Integrante de la fauna de suelo. Entre plantas y en lugares arenosos (Pilsbry, 1901-02).

Material tipo: MHN no. 1840.9.12.50. Probables sintipos. Repositorios: MACN-In 9.899. Paraná, Entre Ríos. Leg. J. Frenguelli. 6 ejs. MLP 1.028.Paraná, Entre Ríos. Col. J.F., 1 ej. Cordobense. MLP 1.307. Arroyo Curtiembre, Entre Ríos. Col. J.F., 34 ejs. Pre-Aimarense. MLP 9.279. Calera Aldasoro, Paraná, Entre Ríos. Col. J.F., 1 ej. Bonaerense?. Registros en el Cuaternario de Argentina: Pleistoceno y Holoceno. Buenos Aires (La Plata, norte de la provincia); ? Bonaerense (Entre Ríos: Paraná); Platense: Buenos Aires (Bahía Blanca); Entre Ríos (Diamante, Paraná, arroyo Curtiembre). 

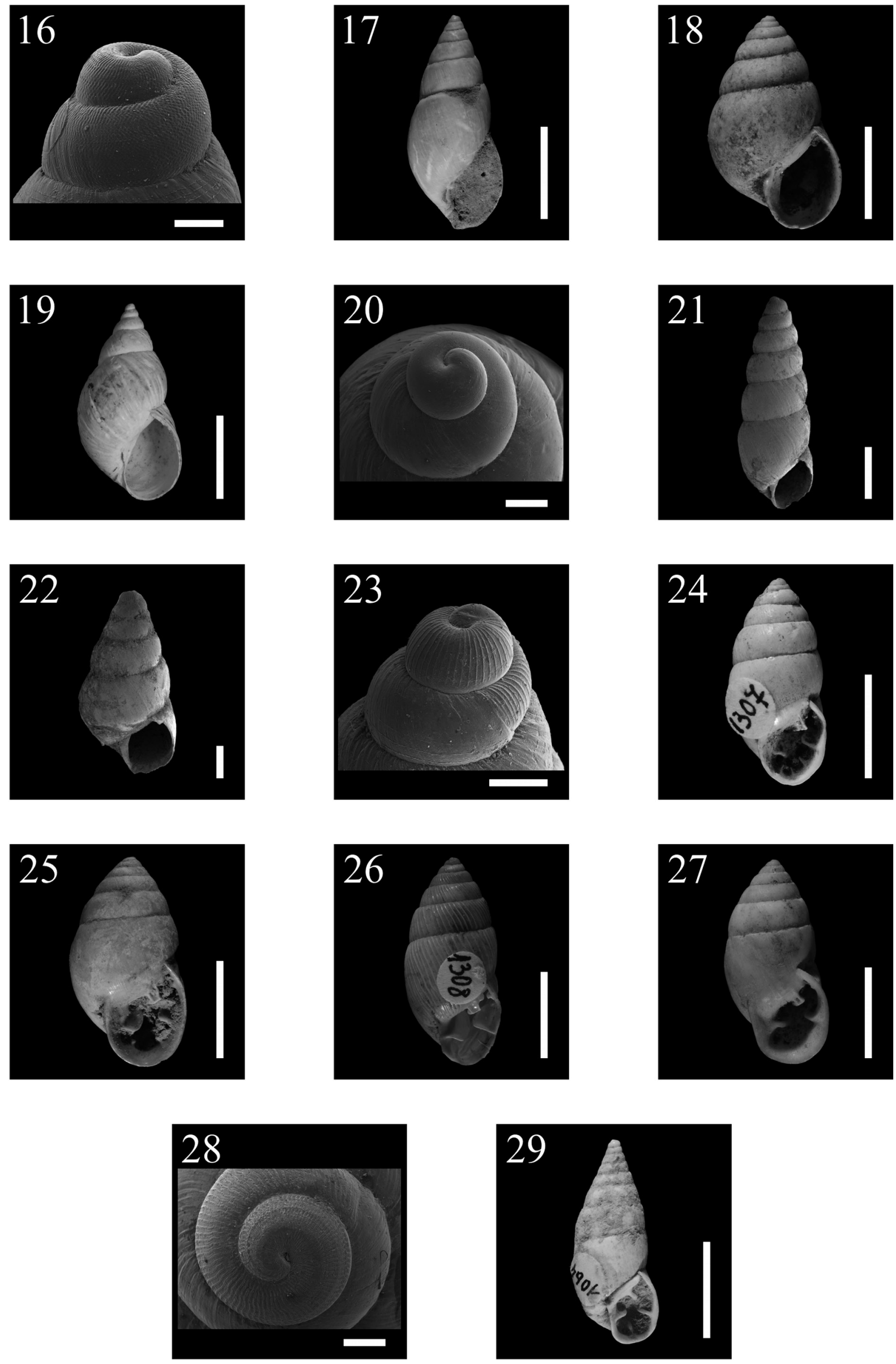


\section{Plagiodontes daedaleus \\ (Deshayes in Férussac \& Deshayes, 1820)}

Fig. 25

*1820. Pupa daedaleus Deshayes in Férussac \& Deshayes: 217.

1875b. Bulimus (Odontostomus) daedaleus (Desh. in Fér. \& Desh.); Doering: 198.
1901-02.Odontostomus (Plagiodontes) deadaleus (Desh. in Fér. \& Desh.); Pilsbry: 97, pl. 14, figs. 1-9.

1907. Plagiodontes daedaleus (Desh. in Fér. \& Desh.); Doering: 177.

v1957. Plagiodontes daedaleus (Desh. in Fér. \& Desh.); Frenguelli: 78; 87, 90, 91; 93.

1969. Plagiodontes daedaleus (Desh. in Fér. \& Desh.); Parodiz: 213.

Figura 16. Protoconcha de B. b. bonariensis: MACN-In 6.433. Orillas de río Paraná, San Nicolás, Buenos Aires. Actual. Escala: 0,4 mm. Protoconch of B. b. bonariensis: MACN-In 6.433. Margin of Paraná river, San Nicolás, Buenos Aires. Modern. Scale: 0.4 mm.

Figura 17. Bulimulus bonariensis sporadicus (d'Orbigny, 1835): MLP 5.902. Bajada Pucará, Capital, Córdoba. Cordobense. Escala: $10 \mathrm{~mm}$.

Bulimulus bonariensis sporadicus (d'Orbigny, 1835): MLP 5.902. Bajada Pucará, Capital, Córdoba. Cordobense. Scale: $10 \mathrm{~mm}$.

Figura 18. Bulimulus rushii Pilsbry, 1897: MLP 1.044. Arroyo de la Curtiembre, Entre Ríos. Pre-Aimarense. Escala: 10 mm. Bulimulus rushii Pilsbry, 1897: MLP 1.044. Arroyo de la Curtiembre, Entre Ríos. Pre-Aimarense. Scale: $10 \mathrm{~mm}$.

Figura 19. Discoleus ameghinoi (Ihering, 1908): MACN-Pi 562. Tipo. Buenos Aires. Pampeano inferior. Escala: 10 mm. Discoleus ameghinoi (Ihering, 1908): MACN-Pi 562. Type. Buenos Aires. Lower Pampian. Scale: $10 \mathrm{~mm}$.

Figura 20. Protoconcha de D. ameghinoi: MACN-In 18.445. Bahía Sanguinetto, Santa Cruz. Actual. Escala: 0,5 mm. Protoconch of D. ameghinoi: MACN-In 18.445. Bahía Sanguinetto, Santa Cruz. Modern. Scale: $0.5 \mathrm{~mm}$.

Figura 21. Naesiotus deletangi (Parodiz, 1946): DCG-MLP-007-822. Villa Valle María (nivel medio), Diamante, Entre Ríos; $2.490 \pm 45$ A.P. Escala: $2 \mathrm{~mm}$.

Naesiotus deletangi (Parodiz, 1946): DCG-MLP-007-822. Villa Valle María (middle level), Diamante, Entre Ríos; $2.490 \pm 45$ A.P. Scale: $2 \mathrm{~mm}$.

Figura 22. Naesiotus pollonerae (Ancey, 1897): DCG-MLP-007-821. Villa Valle María (nivel medio), Diamante, Entre Ríos; $2.490 \pm 45$ A.P. Escala: $1 \mathrm{~mm}$.

Naesiotus pollonerae (Ancey, 1897): DCG-MLP-007-821. Villa Valle María (middle level), Diamante, Entre Ríos; $2.490 \pm 45$ A.P. Scale: $1 \mathrm{~mm}$.

Figura 23. Protoconcha de N. pollonerae: MACN-In 6.435. Barrancas de San Nicolás, río Paraná, Buenos Aires. Actual. Escala: 0,55 mm. Protoconch of N. pollonerae: MACN-In 6.435. Hills of San Nicolás, margin of Paraná river, Buenos Aires. Modern. Scale: $0.55 \mathrm{~mm}$.

Figura 24. Plagiodontes dentatus (Wood, 1828): MLP 1.307. Arroyo Curtiembre, Entre Ríos. Pre-Aimarense. Escala: 10 mm. Plagiodontes dentatus (Wood, 1828): MLP 1.307. Arroyo Curtiembre, Entre Ríos. Pre-Aimarense. Scale: $10 \mathrm{~mm}$.

Figura 25. Plagiodontes daedaleus (Deshayes in Férussac \& Deshayes, 1820): MLP 1.330. Mar Chiquita, borde sur, cerca de la boca del Saladillo. Lujanense. Escala: $10 \mathrm{~mm}$.

Plagiodontes daedaleus (Deshayes in Férussac \& Deshayes, 1820): MLP 1.330. Mar Chiquita, southern margin, in the surroundings of Saladillo outlet. Lujanense. Scale: $10 \mathrm{~mm}$.

Figura 26. Plagiodontes multiplicatus (Doering, 1875): MLP 1.308. Quilino, Córdoba. Actual. Escala: $10 \mathrm{~mm}$. Plagiodontes multiplicatus (Doering, 1875): MLP 1.308. Quilino, Córdoba. Modern. Scale: $10 \mathrm{~mm}$.

Figura 27. Plagiodontes patagonicus (d'Orbigny, 1835): MLP 1.313. Bahía Blanca, camino a Puerto White. Cordobense. Escala: 10 mm. Plagiodontes patagonicus (d'Orbigny, 1835): MLP 1.313. Bahía Blanca, road to Puerto White. Cordobense. Scale: $10 \mathrm{~mm}$.

Figura 28. Protoconcha de P. patagonicus: MACN-In 34.066. Altos de Palihue, Bahía Blanca, Buenos Aires. Actual. Escala: 0,5 mm. Protoconch of P. patagonicus: MACN-In 34.066. Altos de Palihue, Bahía Blanca, Buenos Aires. Modern. Scale: 0.5 mm.

Figura 29. Spixia spixii (d’Orbigny, 1835): MLP 1.064. Calera Aldasoro, Paraná, Entre Ríos. Bonaerense. Escala: 10 mm. Spixia spixii (d'Orbigny, 1835): MLP 1.064. Calera Aldasoro, Paraná, Entre Ríos. Bonaerense. Scale: $10 \mathrm{~mm}$. 
Descripción: Concha ovada, perforada y rimada, de espira cónica, $6 \frac{1}{2}$ a 7 vueltas convexas, incrementadas rápidamente, la última obesa, llevando un poco abajo el labio basal, abertura vertical, ovado-truncada, con 7 dientes, casi cerrada por uno grande, 1 lamela parietal compuesta angular y enroscada, bífida hacia fuera, 1 lamela subvertical muy grande sobre la columela, 2 ó 3 pliegues comprimidos dentro del labio basal, 1 pliegue similar a una placa suprapalatal grande, oblicua y enroscada en el medio del labio externo y 2 pliegues suprapalatales separados, pequeños, tuberculares, ubicada dentro del pliegue palatal inferior hay una barrera transversa erecta, peristoma delgado y expandido; teleoconcha fina y densamente estriada; protoconcha con escultura de microcostillas, color blanco (Pilsbry, 1901-02).

Dimensiones del ejemplar ilustrado (MLP 1.330): 11,3 x $21,2 \mathrm{~mm}$.

Localidad tipo: Desconocida.

Distribución geográfica: Centro-oeste de Argentina. Simone (2006) lo cita para Brasil.

Distribución estratigráfica: Pleistoceno - Reciente.

Hábitat y requerimientos ecológicos: Integrante de la fauna de suelo. En lugares secos y hasta en los márgenes de salinas (Pilsbry, 1901-02).

Material tipo: No localizado.

Repositorios: MACN-In 37.082. Laguna Mar Chiquita, Córdoba. $30^{\circ} 55^{\prime} 13.2^{\prime \prime} \mathrm{S}-62^{\circ} 40^{\prime} 58.8^{\prime \prime} \mathrm{O} .10$ ejs. MLP 1.032. Gral. Paz, entre el Hipódromo y el Hospital Italiano, Córdoba. Precordobense. Col. J.F., 3 ejs. MLP 1.309. Altos de San Vicente, Córdoba. Col. J.F., 24 ejs. Cordobense. MLP 1.316. Boca de la toma del canal San Martín, Santiago del Estero. Col. J.F., 17-VII-1929. 85 ejs. Bonaerense. MLP 1.318. Copacabana, Córdoba. Col. J.F., 19-I-1926. 5 ejs. Post-platense. MLP 1.319. Altos de San Vicente, Córdoba. Col. J.F., 3 ejs. Quequense. MLP 1.320. Mendiolaza, Córdoba. Col. J.F., 4 ejs. Aimarense. MLP 1.321. Colonia Lola, San José, Córdoba. Col. J.F., 2 ejs. Aimarense. MLP 1.324. Colonia Lola, San José, Córdoba. Col. J.F., 5 ejs. Pre-platense. MLP 1.329. Isla Chica, Mar Chiquita, Córdoba. Col. J.F., 16-IV-1930. 44 ejs. Platense. MLP 1.330. Mar Chiquita, borde sur, cerca de la boca del Saladillo. Col. J.F., 17-IV- 1930. 3 ejs. Lujanense. MLP 1.331. Unquillo, Córdoba. Col. J.F., 24 ejs. Precordobense. MLP 4.921. Los Molinos, Calamuchita, Córdoba. Col. J.F., 15 ejs. Cordobense. MLP 9.227. Altos de San Vicente, Córdoba. Col. J.F., 2 ejs. Platense. MLP 9.229. Colonia Lola, San José, Córdoba. Col. J.F., 3 ejs. Bonaerense superior. MLP 9.277. Altos de San Vicente, Córdoba. Col. J.F., 2 ejs. Platense. MLP 9.278. Despeñaderos, Santa María, Córdoba. Col. J.F., 1 ej. Cordobense. Registros en el Cuaternario de Argentina: Pleistoceno y Holoceno. Ensenadense: Córdoba (San Vicente); Bonaerense: Santiago del Estero (canal San Martín); Lujanense (Córdoba: Mar Chiquita); Platense (Córdoba: Calamuchita, Colonia Lola, Copacabana, Despeñaderos, General
Paz, Mar Chiquita, Mendiolaza, San Vicente, Unquillo), Santiago del Estero (río Dulce).

Observaciones: En MLP 1.309 y MLP 1.330 aparece un ejemplar de S. meridionalis. En MLP 1.032 aparecen 3 ejemplares de $B$. apodemetes.

\section{Plagiodontes multiplicatus (Doering, 1875)} Fig. 26

*1875a. Bulimus (Odontostomus) multiplicatus Doering: 452. 1901-02. Odontostomus (Plagiodontes) multiplicatus (Doering); Pilsbry: 101.

1939. Odontostomus (Plagiodontes) multiplicatus (Doering); Parodiz: 718, lám. 1, fig. c.

2003. Plagiodontes multiplicatus (Doering); Pizá \& Cazzaniga: 154.

Descripción: Concha ovada-oblonga, regularmente estriada, espira elongada, profundamente rimada, ápice agudo atenuado, 7 vueltas, un poco convexas, la última cerca de $2 / 3$ de la longitud total, con una débil cresta basal, abertura subvertical, ovada, casi cerrada por 8 a 10 dientes, 3 de ellos grandes, la primera, angulada, retorcida y muesqueada, sobre la pared parietal, la segunda, con forma de lengua, excavada sobre la columela, la tercera, enroscada, dentro del margen derecho, hay también 3 a 5 pliegues pequeños dentro de la pared basal, y dos obsoletos dentro de la parte superior del labio externo, y un pliegue transverso más profundo en la abertura, peristoma algo engrosado, labiado, expandido, un poco reflejado, los márgenes unidos por un callo delgado (Pilsbry, 1901-02).

Dimensiones del ejemplar ilustrado (MLP 1.308): 23,5 $\mathrm{x} 10,8 \mathrm{~mm}$.

Localidad tipo: Cerro Chepe, La Rioja, Argentina. Distribución geográfica: Región central de Argentina. Distribución estratigráfica: Holoceno - Reciente. Hábitat y requerimientos ecológicos: Integrante de la fauna de suelo. No se conocen en detalle.

Material tipo: NHM Sintipo (Pizá \& Cazzaniga, 2003). Repositorios: MACN-In 18.324. 44 ejs. Olta, La Rioja. Leg. M. Gómez, III-1929. MLP 1.308. Quilino, Córdoba, Col. J.F., 30-I-1926. 15 ejs. Reciente. MLP 1.310. Quilino, Córdoba, Col. J.F., 30-I-1926. 74 ejs. Platense. MLP 1.311. Quilino, Córdoba, Col. J.F., 30-I-1926. 60 ejs. Postplatense. MLP 1.312. Cruz del Eje, Córdoba. Col. J.F., 14III-1927. 60 ejs. Cordobense.

Registro en el Cuaternario de Argentina: Holoceno. Platense: Córdoba (Quilino).

Observación: orignalmente con dos subespecies: minor y major. El lote MLP 1.312 presenta dimensiones menores a las de los otros ejemplares (dm.: 8,5 x alt.: 17,8 mm), habiéndola consignado Frenguelli in schedula como Plagiodontes daedaleus var. (Parodiz, 1939, lám., C). El material ilustrado es un registro inédito de la Colección Joaquín Frenguelli. 
Plagiodontes patagonicus (d'Orbigny, 1835) Figs. 27 y 28

*1835. Helix patagonica d'Orbigny: 32.

1837. Pupa sowerbiana patagonica (d'Orb.); d'Orbigny: 321. 1901-02.Odontostomus (Plagiodontes) patagonicus (d'Orb.); Pilsbry: 95, pl. 14, figs. 20-24.

1967. Cyclodontina (Plagiodontes) patagonica (d'Orb.); Camacho: 149, lám. 17, fig 14a, b.

1969. Plagiodontes patagonicus (d’Orb.); Parodiz: 213.

Descripción: Concha pupiforme, con espira cónica corta, profundamente marginada o rimada, $6 \frac{1 / 2}{2}$ a vueltas, última vuelta subcilíndrica a con forma de barril, las otras rápidamente angostándose, última con una carena basal más o menos diferenciada en su última mitad y con una parte aplanada dentro de la carena detrás del labio basal, abertura vertical, breve e irregularmente ovalada, obstruida por 3 láminas principales y 1-2 dentículos más pequeños, 1 lámina curvada bien dentro sobre el labio parietal, bífida en su extremo externo, 1 lámina que entra sobre la columela muy oblicuamente y con pliegue palatal superior, comprimido, dentro del labio externo, cerca de la mitad, algunos ejemplares tienen, además, un pequeño pliegue basal y otro pliegue suprapalatal y otros, poseen 1 ó 2 más, peristoma expandido; teleoconcha con estrías de crecimiento finas, irregulares; protoconcha con escultura de costillas; color blanco (Pilsbry, 1901-02).

Dimensiones del ejemplar ilustrado (MLP 1.313): 21,1 $\mathrm{x} 10,5 \mathrm{~mm}$.

Localidad tipo: Argentina, Buenos Aires, Bahía Blanca. Distribución geográfica: Argentina. Suroeste de la provincia de Buenos Aires.

Distribución estratigráfica: Pleistoceno - Reciente.

Hábitat y requerimientos ecológicos: Integrante de la fauna de suelo, se lo puede encontrar en dunas y a lo largo de ríos (Pilsbry, 1901-02); su alimento parece estar constituído por restos vegetales en descomposición (Cazzaniga \& Delhey, 2002).

Material tipo: MNHN Sintipos (Cazzaniga et al., 2005); NHM 1845.12.4.235. Sintipos.

Repositorios: MACN-In 34.066. Bahía Blanca, Buenos Aires. Col. J. Pizá, X-1997. Pastizal cerca del arroyo Napostá Grande, en Altos de Palihue. 28 ejs. MACN-In 37.488. Estación Grumbein, cerca de Bahía Blanca, Buenos Aires. 45 ejs. MACN-Pi 4.741. Arroyo Napostá, Bahía Blanca. Col. A. Bonnard. 5 ejs. Post-platense. MLP 1.313. Bahía Blanca, camino a Puerto White. Col. J.F., 10-II-1924. 79 ejs. Cordobense. MLP 1.314. Bahía Blanca, subida al cementerio. Col. J.F., 14-IV-1924. 149 ejs. Cordobense. MLP 1.315. Arroyo Napostá, Bahía Blanca. Col. J.F., 10-II-1924. 112 ejs. Precordobense. MLP 1.325. Arroyo Las Mostazas, Coronel Dorrego, Buenos Aires. Col. J.F., 6-IV-1924. 1 ej. fragm. Quequense (Platense, Frenguelli, 1939).
Registros en el Cuaternario de Argentina: Pleistoceno y Holoceno. Pleistoceno: Buenos Aires (Bahía Blanca, sur de la provincia); Platense (Buenos Aires: Bahía Blanca, Coronel Dorrego).

Observación: En el lote MLP 1.315 puede haber dos especies o morfotipos.

\section{Spixia Pilsbry \& Vanatta in Pilsbry, 1898}

Especie tipo: Helix spixii d'Orbigny, 1835

Distribución estratigráfica: Pleistoceno - Reciente (Parodiz, 1969).

Distribución estratigráfica en Argentina: Pleistoceno Reciente (Parodiz, 1969).

\section{Spixia spixii spixii (d'Orbigny, 1835)}

Fig. 29

*1835. Helix spixii d'Orb.: 21.

1901-02.Odontostomus (Spixia) spixi (d'Orb.); Pilsbry: 67, pl. 12, figs. 60-63.

1942. Odontostomus spixi spixi (d’Orb.); Parodiz: 200, lám. 2, fig. 8.

v1957. Odontostomus spixi (d'Orb.); Frenguelli: 76.

1969. Spixia spixi (d’Orb.); Parodiz: 213.

Descripción: Concha turritelada, estrechamente umbilicada, espira alta-cónica, adelgazándose hacia el ápice obtuso, $10 \frac{1}{2}$ a $11 \frac{1}{2}$ vueltas débilmente convexas, la última tiene una abolladura suave debajo del labio externo y un surco profundo detrás del labio basal, abertura pequeña, ovada, o subpentagonal, obstruida por 4 dientes, 1 lamela parietal comprimida, 1 lamela columelar oblicua torcida, 1 pliegue palatal inferior comprimido, basal en posición, y 1 pliegue palatal superior grande en la mitad del labio externo, peristoma débil o moderadamente expandido, el margen columelar dilatado; teleoconcha con estrías desde fuertes a subobsoletas sobre las últimas vueltas; protoconcha con costillas; color castaño (Pilsbry, 1901-02).

Dimensiones del ejemplar ilustrado (MLP 1.064): 21,0 x $8,4 \mathrm{~mm}$.

Localidad tipo: Bolivia, Chiquitos.

Distribución geográfica: Bolivia, Paraguay. En Argentina, región septentrional.

Distribución estratigráfica: Pleistoceno - Reciente.

Hábitat y requerimientos ecológicos: Integrante de la fauna de suelo. No se conocen en detalle.

Material tipo: MHN Sintipo (1) 1854.12.4.232 (Simone, 2006).

Repositorios: MLP 1.064. Calera Aldasoro, Paraná, Entre Ríos. Col. J.F., 12 ejs. Bonaerense. MLP 1.326. Alemania, Salta. Col. J.F., 22-VII-1927. 10 ejs. Reciente. MLP 1.328. Cantera Aldasoro. Paraná, Entre Ríos. Col. J.F., 11 ejs. Bonaerense. MLP 5.904. Unquillo, Córdoba. Col. J.F., 
1 ej. juv. Tehuelchense. MLP 5.918. Unquillo, Córdoba. Col. J.F. 3 ejs. Tehuelchense.

Obs.: el lote MLP 1.328 contiene ejemplares de esta especie y de $S$. tucumanensis.

Registros en el Cuaternario de Argentina: Pleistoceno y Holoceno. Bonaerense (Entre Ríos: Paraná); Platense (Córdoba: Colonia Lola, Unquillo).

Observación: Originalmente con dos subespecies: minor y major. La primera tiene los representantes fósiles que se indican. Simone (2006) la considera sinónimo junior de Spixia striata (Spix, 1827). Se trataría de la subespecie nominotípica.

El ejemplar ilustrado corresponde a la "variedad" $m a$ jor de d'Orbigny, subespecie nominotípica de acuerdo a Parodiz (1942).

\section{Spixia charpentieri (Grateloup in Pfeiffer, 1851)} Figs. 30 y 31

*1851. Bulimus Charpentieri Grateloup in Pfeiffer: 14

1875a. Bulimus (Odontostomus) Charpentieri (Grat. in Pfr.); Doering: 455.

1901-02.Odontostomus (Spixia) charpentieri (Grat. in Pfr.); Pilsbry: 76 , pl. 12, figs. 75-77.

1907. Odontostomus Charpentieri (Grat. in Pfr.); Doering: 177. v1957. Odontostomus charpentieri (Grat. in Pfr.); Frenguelli: 90. 1967. Cyclodontina (Spixia) charpentieri (Grat. in Pfr.); Camacho: 149.

1969. Spixia charpentieri (Grat. in Pfr.); Parodiz: 213.

Descripción: Concha fusiforme-oblonga, rimada-subperforada, espira turritelada, el ápice algo obtusamente atenuado, 10 vueltas poco convexas, la última escasamente excediendo $1 / 4$ de la longitud con hoyuelos en la base y en el lado detrás de la abertura, abertura ovalada-oblonga, con 5 dientes, uno sobre la pared parietal, otra lámina horizontal sobre la columela, el tercer diente, basal, $4^{\mathrm{o}}$ y $5^{\mathrm{o}}$ dientes pequeños, dentro del borde recto, peristoma simple, los bordes unidos por un callo delgado, borde recto, margen derecho estrechamente expandido, borde columelar anchamente reflejado; teleoconcha muy delicadamente estriada; protoconcha con costillas; color castaño (Pilsbry, 1901-02).

Dimensiones del ejemplar ilustrado (MLP 30.751): 20,0 x $6,0 \mathrm{~mm}$.

Localidad tipo: Córdoba.

Distribución geográfica: En Argentina, región central. Simone (2006) la registra para Brasil.

Distribución estratigráfica: Pleistoceno - Reciente.

Hábitat y requerimientos ecológicos: Integrante de la fauna de suelo. Son abundantes bajo piedras (Pilsbry, 1901-02).

Material tipo: MHN Sintipo (Simone, 2006).

Repositorios: MACN-In 14.834. Alrededores de Córdoba. Leg. J. Frenguelli, XI-1923. 144 ejs. MACN-In 30.749. Córdoba. Col. C. Berg, III-1875. 7 ejs. MACN-In 30.751. Puerta de Ambato, Catamarca. Col. Palavecino, 1944. 2 ejs. Det. M. E. Salas Oroño, 2009.
Registros en el Cuaternario de Argentina: Pleistoceno medio - tardío: Buenos Aires (Miramar), Córdoba (Santa María); Bonaerense: Miramar, sur de Buenos Aires; Platense: Córdoba (Capital).

Observación: Los registros cuaternarios de esta especie no se han podido confirmar, debido a la inexistencia de los materiales referidos y de ilustraciones en la bibliografía citada. Simone (2006) ilustra un ejemplar sintipo, dando como distribución de la especie a Brasil.

\section{Spixia tucumanensis Parodiz, 1941}

Fig. 32

*1941. Odontostomus (Spixia) tucumanensis Parodiz: 92, lám. 7, figs. 10-13, 16

1942. Odontostomus (Spixia) tucumanensis (Parodiz); Parodiz: 319, lám. 1, fig. 1.

1969. Spixia tucumanensis (Parodiz); Parodiz: 213.

1990. Spixia tucumanensis (Parodiz); Cuezzo: 201, lám. 2, fig. 3.

2007. Spixia tucumanensis (Parodiz); Salas Oroño: 1498, lám. 20, figs. 39-49.

Descripción: Concha ovada, cónica, bastante larga, con 9 $1 / 2$ vueltas débilmente convexas con escultura axial rugosa e irregular, última vuelta globosa, casi lisa, de cerca 1 1/2 la longitud total de la concha, suturas no profundas pero bien definidas, abertura ovada, con peristoma reflejado y conteniendo 5 dientes bien desarrollados, similares a las de otras especies del género, callo de unión parietal variable; teleoconcha con vestigios de líneas espirales; protoconcha con 2 vueltas iniciales débil y finamente esculpidas; color castaño.

Dimensiones del ejemplar ilustrado (MACN-In 23.108): $25,5 \times 9,2 \mathrm{~mm}$.

Localidad tipo: Márgenes del río Sali, cerca de la cuidad de Tucumán.

Distribución geográfica: Argentina: Tucumán.

Distribución estratigráfica: Bonaerense - Reciente.

Hábitat y requerimientos ecológicos: Bajo piedras y entre raíces y porción basal de pequeños arbustos (Salas Oroño, 2007).

Material tipo: Holotipo: MACN-In 23.108 (Tablado \& Mantinian, 2004).

Repositorios: Holotipo: MACN-In 23.108. Orillas del río Salí, Tucumán. Leg. R. Scheiter, 1919. MACN-In 21.478. Tucumán. Leg. R. Schreiter, 1933. 330 ejs.; MLP 1.327. Colonia Lola, San José, Córdoba. Col. J.F., 17 ejs. Preplatense. MLP 1.328. Cantera Aldasoro, Paraná, Entre Ríos. Col. J.F., 6 ejs. Bonaerense; PIL 13510. Tafí Viejo, Tucumán. Pleistoceno: ? Lujanense. 1 ej.

Obs.: El lote MLP 1.328 contiene ejemplares de S. spixii $\mathrm{y}$ esta especie.

Registros en el Cuaternario de Argentina: Pleistoceno Holoceno?. Bonaerense: Entre Ríos (Parodiz, 1969: 213); ? Lujanense: Tucumán (Tafí Viejo). 
Superfamilia Streptaxoidea Gray, 1860

Familia Scolodontidae Baker, 1925 (= Systrophiidae Thiele, 1927)

\section{Scolodonta Doering, 1875}

Especie tipo: Streptaxis (Scolodonta) semperi Doering, $1875 \mathrm{a}$.

Distribución estratigráfica: Ensenadense tardío - Reciente (Voglino \& Pardiñas, 2005).

Distribución estratigráfica en Argentina: Ensenadense tardío - Reciente (Voglino \& Pardiñas, 2005).

\section{Scolodonta semperi Doering, 1875}

Figs. 33 y 34

\footnotetext{
*1875a. Streptaxis (Scolodonta) Semperi Doering: 439.

1907. Scolodonta Semperi (Doering); Doering: 177.

v1957. Scolodonta semperi (Doering); Frenguelli: 90; 91.

1967. Scolodonta semperi (Doering); Camacho: 155, lám. 19, fig. $9 \mathrm{a}, \mathrm{b}$.

1990. Scolodonta semperi (Doering); Cuezzo: 200, lám. 2, fig. 5.

v2001. Scolodonta semperi (Doering); Tonni et al.: 2.

v2011. Scolodonta semperi (Doering); Aguirre et al.: 13, figs. $4(6-8,11-13)$ y $5(5-7)$.
}

Descripción: Concha pequeña, discoidal, transparente, ampliamente umbilicada, espira muuy baja, sobrepasando apenas la última vuelta, 4,5-5 vueltas convexas de crecimiento regular, abertura circular, recortada por la saliente de la vuelta en forma de media luna, peristoma simple, cortante, de bordes bien separados y sin revestimiento parietal, ombligo perspectivo, la sutura profunda, teleoconcha con estrías transversales finas, irregulares; protoconcha lisa, color córneo.

Dimensiones del material ilustrado (DCG-MLP-007-816): $3,60 \times 1,5 \mathrm{~mm}$.

Localidad tipo: Valle del río Primero (sierra de Córdoba) y bosques de Jesús María, Córdoba, y Villa Vicencio, sierra de Mendoza, Mendoza, Argentina.

Distribución geográfica: En Argentina, en el norte y centro del país. Citada para Paraguay.

Distribución estratigráfica: Lujanense?, Pleistoceno Holoceno tardío - Reciente.

Hábitat y requerimientos ecológicos: Terrestres, geófilos, en cobertura vegetal, bajo hojas podridas, debajo de troncos podridos, en lugares umbrosos (Doering, 1875a,b, 1877). Carnívoros.

Material tipo: Streptaxis (Scolodonta) Semperi: Sintipos (2): MACN-In 13.885 (Tablado \& Mantinian, 2004).

Repositorios: DCG-MLP-007-816(A). Villa Valle María (nivel inferior), Diamante, Entre Ríos; 2.490 \pm 45 A.P. 12 ejs.; DCG-MLP-007-823(B). Villa Valle María (nivel medio), Diamante, Entre Ríos; $2.490 \pm 45$ A.P. 6 ejs.; DCG-
MLP-007-824. Villa Valle María (nivel medio), Diamante, Entre Ríos; $2.490 \pm 45$ A.P.; 5 ejs.; DCG-MLP-007-829. Villa Valle María (nivel superior), Diamante, Entre Ríos;

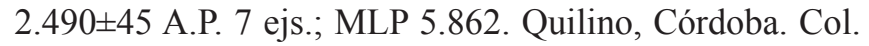
J.F., 5 ejs. Platense. MLP 5.863. Ramal A, Río Cuarto, Córdoba. Col. J.F., 2 ejs. Platense. MLP 5.864. Gral. Paz, Córdoba. Col. J.F., 12 ejs. Post-Cordobense. MLP 5.865. El Brete, Paraná, Entre Ríos. Col. J.F., 1 ej. Cordobense. MLP 5.867. SW de Punta Hermengo, Miramar, Buenos Aires. Col. J.F., 1 ej. Bonaerense. MLP 5.868. Nueva Córdoba, Capital, Córdoba. Col. J.F., 1 ej. Cordobense. MLP 5.871. Colonia Lola, San José, Córdoba. Col. J.F., 2 ejs. Cordobense; MAS PALEOINV 274. Villa Valle María (nivel inferior), Diamante, Entre Ríos; $2.490 \pm 45$ A.P. 1 ej.; PIL 13.508. Tafí Viejo, Tucumán. Pleistoceno: ? Lujanense. 7 ejs.; MACN-Pi 4.739. Bajada del balneario de Aldea Valle María. Col. E. Tonni, 2000. 4 ejs. Holoceno. Registros en el Cuaternario de Argentina: Pleistoceno y Holoceno. Bonaerense (Buenos Aires: Miramar), Córdoba (Santa María); ? Lujanense: Tucumán (Tafí Viejo); Platense: Buenos Aires (río Luján), Córdoba (Capital, Colonia Lola, General Paz, Río Cuarto, Quilino, San Vicente); Entre Ríos (Paraná); Pleistoceno tardío: Mendoza; Holoceno tardío (Entre Ríos: Diamante).

\section{Scolodonta argentina (Strobel, 1874)} Fig. 35

\footnotetext{
*1874. Hyalina (Ammonoceras) argentina Strobel: 9, Tav. 1, fig. 1.

1877. Streptaxis (Scolononta) (sic) Argentina (Strobel); Doering: 229.

1878. Streptaxis (Scolodonta) Argentina (Strobel); Doering: 310.

1885. Streptaxis argentina (Strobel); Tryon: 66, pl. 13, figs. 58-60.

v1920. Scolodonta argentina (Strobel); Frenguelli: 162, 249.
}

Descripción: Concha orbicular, frágil, espira deprimida, ampliamente umbilicada, 5 vueltas aplanadas, de crecimiento lento, sutura profunda, abertura descendente, abertura oblicua, lunada-subcircular, peristoma subreflejado, callo rudimentario, ombligo perspectivo; teleoconcha con vueltas tenuemente estriadas; protoconcha lisa; color blanco.

Dimensiones del material ilustrado (MLP 5.861): 5,8 $\mathrm{x} 2,5 \mathrm{~mm}$.

Localidad tipo: Mendoza y Bahía Blanca, Argentina (véase comentario de Doering, 1877 y 1878).

Distribución geográfica: Argentina: Mendoza y Bahía Blanca.

Distribución estratigráfica: Pleistoceno - Reciente.

Hábitat y requerimientos ecológicos: Terrestres, geófilos, entre las grietas de las rocas de lugares húmedos, en cercanías de corrientes de agua. Carnívoros.

Material tipo: No fue localizado. 
Repositorio: MLP 5.861. Bajada Pucará, Capital, Córdoba. Col. J.F., 1 ej. Cordobense.

Registros en el Cuaternario de Argentina: Pleistoceno y Holoceno. Bonaerense: Córdoba (Capital), Entre Ríos (Paraná); Platense (Córdoba: Capital); Holoceno: Córdoba (Capital), Entre Ríos (Paraná).

Observación: Los ejemplares del lote MLP 5.861 no parecen corresponderse a la especie $S$. argentina, que no ha vuelto a ser encontrada desde su descripción original, sino a $S$. semperi.

\section{Miradiscops Baker, 1925}

Especie tipo: Miradiscpos variolata Baker, 1925.

Sinónimo: Microhappia Thiele, 1927.

Distribución estratigráfica: Holoceno medio - Reciente (Miquel \& Steffan, 2005; Aguirre et al., 2011).

Distribución estratigráfica en Argentina: Holoceno medio - Reciente (Miquel \& Steffan, 2005; Aguirre et al., 2011).

Miradiscops brasiliensis (Thiele, 1927) Fig. 36

*1927. Microhappia brasiliensis Thiele: 320, fig. 17 a-c. 1959-60.Miradiscops (Punctodiscops) brasiliensis (Thiele); Zilch: 545, fig. 1907.

1997. Scolodonta semperi (Doering) Miquel \& Parent: 110, fig. 4 (error de identificación).

v2005. Miradiscops brasiliensis (Thiele); Miquel \& Steffan: 495.

v2011. Miradiscops brasiliensis (Thiele); Aguirre et al.: 13, Figs. 4 (1-3) y 5 (1-3).

Descripción: Concha pequeña, subdiscoidal, hialina, espira apenas desarrollada, 5 vueltas regularmente convexas, creciendo lentamente, última vuelta apenas mayor que las anteriores, ombligo abierto (1/3), peristoma cortante; teleoconcha con estrías radiales densas; protoconcha con estrías regulares; color castaño suave.

Dimensiones del ejemplar ilustrado (MLP 5.872): 2,2 $\mathrm{x} 1,1 \mathrm{~mm}$.

Localidad tipo: Brasil: Gorduras.

Distribución geográfica: Brasil, Paraguay, Uruguay. En Argentina, en la Mesopotamia y en el norte y centro del país.

Distribución estratigráfica: Holoceno medio - Reciente. Hábitat y requerimientos ecológicos: Terrestres, geófilos, en cobertura vegetal de ambientes húmedos. Carnívoros. Material tipo: Sintipos: ZMB 102998; ZMB 102999 (Simone, 2006).

Repositorio: DCG-MLP-007-815. Villa Valle María (nivel inferior), Diamante, Entre Ríos; $2.490 \pm 45$ A.P. 2 ejs.; DCG-MLP-007-816(B). Villa Valle María (nivel inferior), Diamante, Entre Ríos; $2.490 \pm 45$ A.P. 2 ejs.; DCG-MLP007-823(A). Villa Valle María (nivel medio), Diamante,
Entre Ríos; $2.490 \pm 45$ A.P. 6 ejs.; DCG-MLP-007-828. Villa Valle María (nivel superior), Diamante, Entre Ríos; $2.490 \pm 45$ A.P.; 3 ejs.; MACN-Pi 4.734. Sitio arqueológico Paso Otero 1. Río Quequén Grande. Col. P. Steffan. 2 ejs. Holoceno medio; MLP 5.872, Punta Carretas, Montevideo; col. J.F., 2 ejs.; MAS PALEOINV 273. Villa Valle María (nivel inferior), Diamante, Entre Ríos; $2.490 \pm 45$ A.P. 1 ej. Registros en el Cuaternario de Argentina: Holoceno medio (Buenos Aires: río Quequén Grande); Holoceno tardío (Entre Ríos: Diamante).

Superfamilia Helicoidea Rafinesque, 1815

Familia Xanthonychidae Strebel \& Pfeffer, 1879

\section{Epiphragmophora Doering, 1875}

Especie tipo: E piphragmophora hieronymi Doering, 1875a, por designación subsiguiente (Pilsbry, 1894).

Distribución estratigráfica: ?Lujanense - Reciente (Cuezzo, 1990).

Distribución estratigráfica en Argentina: ?Lujanense Reciente (Cuezzo, 1990).

\section{Epiphragmophora rhathymos (Holmberg, 1912)} Fig. 37

*1875a. Helix (Eurycampta) monographa Doering: 450.

1907. Eurycampta monographa (Doering); Doering: 175.

1912. Helix (Eurycampta) rhathymos Holmberg: 20.

v1957. Eurycampta monographa (Doering); Frenguelli: 90, 91.

2006. Epiphragmophora rhathymos (Holmberg); Cuezzo: 148, 4D, 12D-E, 20.

Descripción: Concha mediana a grande, subglobosa, semisólida, espira cónica, $4 \frac{1}{2} 2$ vueltas convexas, sutura profunda, última vuelta descendiendo abruptamente hacia la abertura, abertura circular con peristoma reflejado grueso, espacio parietal entre los labios superior e inferior estrecho, ombligo profundo, estrecho, parcialmente cubierto por el labio peristomial columelar basal; teleoconcha con líneas de crecimiento y líneas periféricas muy delgadas, dándole una apariencia de superficie maleada; protoconcha lisa; color blanco, con la última vuelta con banda ecuatorial periférica, que también bordea la sutura.

Dimensiones del ejemplar ilustrado (MACN 1.289): $30,0 \times 13,1 \mathrm{~mm}$.

Localidad tipo: Argentina, Catamarca, El Desmonte. Distribución geográfica: Argentina: Catamarca, Salta, Tucumán y Córdoba.

Distribución estratigráfica: Pleistoceno superior - Reciente.

Hábitat y requerimientos ecológicos: Bajo rocas y adheridas a paredes en estrechas grietas rocosas. En hábitats xerofílicos entre 600 y $2000 \mathrm{~m}$. 
Material tipo: Helix (Eurycampta) rhathymos: Lectotipo: SMF 20397; Paralectotipos (2): MACN-In 1.289 (Tablado \& Mantinian, 2004).

Repositorios: Sintipos (2). MACN-In 1.289: El Desmonte, Catamarca. Col. Holmberg. MLP 1.053. Isla Chica, Mar Chiquita, Córdoba. Col. J.F., 18-IV-1930. 10 ejs. Platense. MLP 1.059. Córdoba. Col. J.F. 27 ejs. Cordobense. MLP 1.062. Colonia Lola, San José, Córdoba. Col. J.F., 2 ejs. Pre-platense?.

Registros en el Cuaternario de Argentina: Pleistoceno y Holoceno. Pleistoceno superior: Córdoba (Santa María); Platense (Córdoba: Colonia Lola, Mar Chiquita).

Observaciones: El ejemplar ilustrado es similar a E. trigrammephora, ya que es un lote mixto.

\section{Epiphragmophora trenquelleonis (Grateloup in Pfeiffer, 1851)} Fig. 38

*1851. Helix trenquelleonis Grateloup in Pfeiffer: 13.

1875b. Helix grupo Eurycampta Trenquelleonis (Grat. in Pfr.); Doering: 156.

1888. Epiphragmophora trenquelleonis (Grat. in Pfr.); Tryon: 82 , pl. 18 , fig. 59.

v1957. Eurycampta trenquelleonis (Grat. in Pfr.); Frenguelli: 78. 2006. Epiphragmophora trenquelleonis (Grat. in Pfr.); Cuezzo: 153, figs. 6B, 14A, C, 21.

Descripción: Concha de tamaño mediano, helicoide, subglobosa, semisólida, espira cónica, 4 1/2 vueltas convexas, última vuelta descendiendo detrás de la apertura, abertura circular con peristoma suavemente reflejado y delgado, espacio parietal entre los labios estrecho, ombligo profundo parcialmente cubierto por el labio peristomeal columelar basal, sutura profunda; teleoconcha con líneas de crecimiento degadas o con bordes de crecimiento gruesos regularmente separados y líneas transversas delicadas entre ellas cortando transversalmente las costillas axiales; protoconcha lisa; color blanco con una banda periférica ecuatorial castaña en la última vuelta que, usualmente, también acompaña a la sutura.

Dimensiones del ejemplar ilustrado (MLP 1.046): 26,2 x $21,6 \mathrm{~mm}$.

Localidad tipo: Argentina, Córdoba.

Distribución geográfica: Bolivia, Paraguay. Argentina: Córdoba, Santiago del Estero, San Luis, Catamarca, La Rioja, Chaco y Formosa.

Distribución estratigráfica: Holoceno - Reciente.

Hábitat y requerimientos ecológicos: Integrante de la fauna de suelo. No se conocen en detalle.

Material tipo: Lectotipo: SMF 7708.

Repositorios: MLP 1.045. Gral. Paz, Córdoba, entre el Hospital Italiano y el Hipódromo. Col. J.F., 9 ejs. Precordobense. MLP 1.046. Arroyo Calchín, Colonia Videla, Córdoba. Col. J.F., 12 ejs. Cordobense. MLP 1.052. Arroyo
Calchín, Colonia Videla, Córdoba. Col. J.F., 40 ejs. Cordobense. MLP 1.058. Altos de San Vicente, Córdoba. Col. J.F., 37 ejs. Cordobense. MLP 1.060. Gral. Paz, Córdoba, entre el Hospital Italiano y el Hipódromo. Col. J.F., 1 ej. Pre-cordobense. MLP 1.061. Altos de San Vicente, Córdoba. Col. J.F., 7 ejs. Quequense.

Registros en el Cuaternario de Argentina: Holoceno. Platense (Córdoba: Capital, General Paz, San Vicente, Colonia Videla).

\section{Epiphragmophora trigrammephora (d'Orbigny, 1835)}

Fig. 39

\section{*1835. Helix trigrammephora d'Orbigny: 22. \\ 1837. Helix trigrammephora (d'Orb.); d'Orbigny: 242, pl. 25, fig. 9-11. \\ 1897. Epiphragmophora trigrammephora (d'Orb.); Ancey: 10. 1990. Epiphragmophora trigrammephora (d'Orb.); Cuezzo: 200. \\ 2006. Epiphragmophora trigrammephora (d'Orb.); Cuezzo: 159, figs. 5D, 15C, D, 19, 21.}

Descripción: Concha helicoide, sbglobosa, semisólida, tamaño mediano, $4 \frac{3 / 4}{4}$ a $5 \frac{3}{4}$ vueltas convexos, usualmente con espira cónica alta, última vuelta descendiendo abruptamente hacia la abertura, sutura profunda impresa, abertura subcuadrangular o subovoidal, peristoma delgado, delicado, expandido, debilmente reflejado, ombligo profundo y amplio; teleoconcha con las primeras vueltas con líneas de crecimiento delgadas, superficie generalmente maleada, con costillas diagonales y líneas de crecimiento transversas interrumpidas por costillas axiales en la última vuelta, en algunos especímenes la última vuelta tiene gruesas líneas de crecimiento axiales en la superficie maleada; protoconcha lisa; color blanco con tres bandas periféricas de color castaño oscuro claramente delimitadas en la última vuelta, la banda superior corre centralmente en cada vuelta de la espira, usualmente la banda central es debilmente más ancha y más pigmentada que las otras.

Dimensiones del ejemplar ilustrado (MLP 32.899): 12,0 x $28,1 \mathrm{~mm}$.

Localidad tipo: Márgenes de Río Grande, Valle Grande y Pampa Grande, Santa Cruz, Bolivia.

Distribución geográfica: Bolivia, Paraguay. Argentina: Jujuy, Salta, Tucumán, Santiago del Estero, Formosa y Chaco (provincia biogeográficas de Chaco y Yungas, Cuezzo, 2006).

Distribución estratigráfica: ?Lujanense (Cuezzo, 1990). Hábitat y requerimientos ecológicos: Debajo de rocas y ramas de árboles, desde los 200 a los $1.600 \mathrm{msnm}$.

Material tipo: MNHN s/n y NHM s/n (Cuezzo, 2006).

Repositorio: MACN-In 32.899. Campo Durán, Tartagal, Salta. Col. E. Feruglio, VIII-1930. 10 ejs.

Registro en el Cuaternario de Argentina: ? Lujanense (Tucumán: Tafí Viejo). 

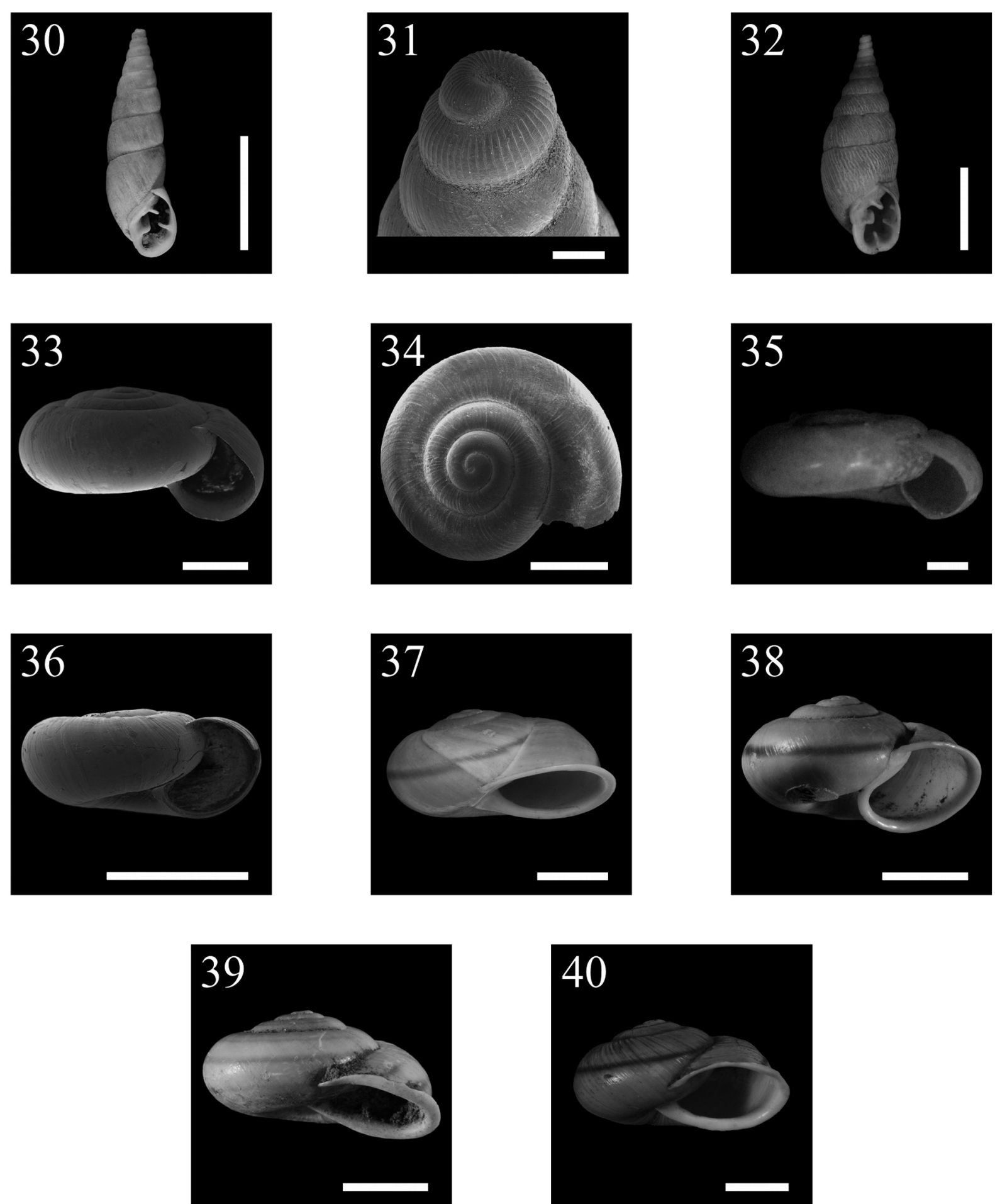

Figura 30. Spixia charpentieri (Grateloup in Pfeiffer, 1850): MLP 30.751. Puerta de Ambato, Catamarca. Actual. Escala: 10 mm. Spixia charpentieri (Grateloup in Pfeiffer, 1850): MLP 30.751. Puerta de Ambato, Catamarca. Modern. Scale: $10 \mathrm{~mm}$.

Figura 31. Protoconcha de S. charpentieri: MACN-In 14.834. Alrededores de Córdoba. Actual. Escala: $0,5 \mathrm{~mm}$. Protoconch of S. charpentieri: MACN-In 14.834. Surroundings of Córdoba. Modern. Scale: $0.5 \mathrm{~mm}$.

Figura 32. Spixia tucumanensis Parodiz, 1941: MACN-In 23.108. Holotipo. Márgenes del río Salí, cerca de la cuidad de Tucumán. Actual. Escala: $10 \mathrm{~mm}$.

Spixia tucumanensis Parodiz, 1941: MACN-In 23.108. Holotype. Margins of Salí river, near Tucumán (city). Modern. Scale: $10 \mathrm{~mm}$. 
Epiphragmophora tucumanensis (Doering, 1875) Fig. 40

*1875a. Helix grupo Aglaja estella tucumanensis Doering: 445. 1875b. Helix (Aglaja) Estella tucumanensis (Doering); Doering: 163.

1894. Epiphragmophora tucumanensis (Doering); Pilsbry: 198. 1990. Epiphragmophora tucumanensis (Doering); Cuezzo: 200, lám. 1, fig. 2.

2006. Epiphragmophora tucumanensis (Doering); Cuezzo: 163, figs. 6A, 14D, E, 19.

Descripción: Concha helicoide, globosa, sólida, espira cónica elevada, tamaño mediano a grande, 4 3/4 a 5 vueltas convexas, última vuelta descendiendo hacia la abertura, sutura profunda impresa, abertura subcircular a ovoide, peristoma grueso reflejado, algunos especímenes con labio basal engrosado, ombligo estrecho, parcialmente cubierto por los márgenes de los labios peristomales; teleoconcha con bandas axiales, superficie de la última vuelta maleada a reticulada; protoconcha lisa; color blanco con una banda gruesa supraecuatorial castaña oscura más notable en la periferia de la última vuelta.
Dimensiones del ejemplar ilustrado (MLP 9.009): 13,4 x $30,0 \mathrm{~mm}$.

Localidad tipo: Argentina, Tucumán, en la pendiente del Oeste de la Sierra de Tucumán, en bosques exhuberantes, a $500-900 \mathrm{~m}$ de altura (Cuezzo, 2006).

Distribución geográfica: Argentina, Tucumán y Catamarca.

Distribución estratigráfica: Lujanense?, Pleistoceno Reciente.

Hábitat y requerimientos ecológicos: En la Yunga, entre 500 y $1800 \mathrm{~m}$, bajo troncos o reptando activamente sobre hojas muertas en el suelo (Cuezzo, 2006).

Material tipo: Lectotipo: SMF (SKF) 7711 [SMF 7710 (Zilch, 1971)].

Repositorio: MACN-In 9.009. Cumbre, Parque Aconquija, Tucumán. Leg. R. Scheiter, 12-II-1917. 1 ej. MACN-In 1.295. Tapia, Tucumán, 700 m. Leg. M. Rodríguez, 8-XII1908. Col. E. Holmberg. 11 ejs. MACN-In 17.598. Cerro Alemania, Salta. Col. J.F.,XII-1927. 5 ejs.; PIL 13506. Tafí Viejo, Tucumán. Pleistoceno: ? Lujanense. 2 ejs. juvs. Registro en el Cuaternario de Argentina: ? Lujanense (Tucumán: Tafí Viejo).

Figura 33. Scolodonta semperi Doering, 1875: DCG-MLP-007-816 (A). Villa Valle María (nivel inferior), Diamante, Entre Ríos; $2.490 \pm 45$ A.P. Vista apertural. Escala: $1 \mathrm{~mm}$.

Scolodonta semperi Doering, 1875: DCG-MLP-007-816 (A). Villa Valle María (lower level), Diamante, Entre Ríos; $2.490 \pm 45$ A.P. Apertural view. Scale: $1 \mathrm{~mm}$.

Figura 34. Scolodonta semperi Doering, 1875: DCG-MLP-007-823 (B). Villa Valle María (nivel inferior), Diamante, Entre Ríos; $2.490 \pm 45$ A.P. Vista apical. Escala: $1 \mathrm{~mm}$.

Scolodonta semperi Doering, 1875: DCG-MLP-007-823 (B). Villa Valle María (lower level), Diamante, Entre Ríos; $2.490 \pm 45$ B.P. Apical view. Scale: $1 \mathrm{~mm}$.

Figura 35. Scolodonta argentina (Strobel, 1874): MLP 5.861. Bajada Pucará, Capital, Córdoba. Cordobense. Escala: 5 mm. Scolodonta argentina (Strobel, 1874): MLP 5.861. Bajada Pucará, Capital, Córdoba. Cordobense. Scale: 5 mm.

Figura 36. Miradiscops brasiliensis (Thiele, 1927): MACN-Pi 4.734. Sitio arqueológico Paso Otero 1. Río Quequén Grande. Holoceno medio. Escala: $1 \mathrm{~mm}$.

Miradiscops brasiliensis (Thiele, 1927): MACN-Pi 4.734. Archaeological site Paso Otero 1. Quequén Grande river. Middle Holocene. Scale: $1 \mathrm{~mm}$.

Figura 37. Epiphragmophora rhathymos (Holmberg, 1912): MACN-In 1.289. Paralectotipo. El Desmonte, Catamarca. Actual. Escala: $10 \mathrm{~mm}$.

Epiphragmophora rhathymos (Holmberg, 1912): MACN-In 1.289. Paralectotype. El Desmonte, Catamarca. Modern. Scale: $10 \mathrm{~mm}$.

Figura 38. Epiphragmophora trenquelleonis (Grateloup in Pfeiffer, 1851): MLP 1.046. Arroyo Calchín, Colonia Videla, Córdoba. Cordobense. Escala: $10 \mathrm{~mm}$.

Epiphragmophora trenquelleonis (Grateloup in Pfeiffer, 1851): MLP 1.046. Arroyo Calchín, Colonia Videla, Córdoba. Cordobense. Scale: $10 \mathrm{~mm}$.

Figura 39. Epiphragmophora trigrammephora (d'Orbigny, 1835): MLP 32.899. Campo Durán, Tartagal, Salta. Actual. Escala: 10 mm. Epiphragmophora trigrammephora (d'Orbigny, 1835): MLP 32.899. Campo Durán, Tartagal, Salta. Modern. Scale: $10 \mathrm{~mm}$

Figura 40. Epiphragmophora tucumanensis (Doering, 1875): MLP 9.009. Cumbre, Parque Aconquija, Tucumán. Actual. Escala: 10 mm. Epiphragmophora tucumanensis (Doering, 1875): MLP 9.009. Cumbre, Parque Aconquija, Tucumán. Modern. Scale: 10 mm 


\section{CONSIDERACIONES FINALES}

De acuerdo con la presente revisión, 16 géneros terrestres de moluscos gasterópodos (Gastrocopta, Succinea, Radiodiscus, Retidiscus, Rotadiscus, Cecilioides, Austroborus, Megalobulimus, Bulimulus, Discoleus, Naesiotus, Plagiodontes, Spixia, Scolodonta, Miradiscops y Epiphragmophora) aparecen representados en el escenario del Cuaternario continental argentino en distintas unidades crono o litoestratigráficas (Fig. 1a).

Prácticamente la totalidad de las especies documentadas en el presente trabajo fueron originalmente descriptas sobre la base de ejemplares modernos y todas ellas cuentan con representantes vivientes en la Región Neotropical. Dos de ellas, Succinea rosariensis Döring y Scolodonta argentina Doering, descriptas como taxones modernos, requieren de confirmación acerca de su validez taxonómica.

Por tradición de estudio y menor dificultad en su identificación, la fracción mejor conocida de los moluscos del Cuaternario corresponde a aquellas b,especies de mediano y gran tamaño (Succinea, Austroborus, Megalobulimus, Bulimulus, Discoleus, Naesiotus, Plagiodontes, Spixia, Scolodonta y Epiphragmophora), en tanto que resultan escasas las citas de taxones de talla inferior a $5 \mathrm{~mm}$ ( Gas trocopta, Radiodiscus, Retidiscus, Rotadiscus, Cecilioides y Miradiscops). Cerca del 60\% de las especies registradas pertenecen a la familia Orthalicidae (= Bulimulidae), un grupo de amplia representación actual en Argentina y América del Sur, con formas fósiles desde el Eoceno (Miquel $\&$ Bellosi, 2010). Por su parte, Strophocheilidae incluye $15 \%$ de esos registros, en tanto que familias como Xanthonychidae, Charopidae y Scolodontidae aportan, cada una, cerca del $10 \%$ de las especies.

Los géneros que se registran con anterioridad al Cuaternario son Austroborus, Megalobulimus, Radiodiscus y Rotadiscus, presentes desde el Eoceno (Miquel \& Bellosi, 2010), además de Succinea (Doering, 1884c: 22). En la presente lista, podría incluirse a Bulimulus, de considerarse co-genérica la especie Paleobulimulus eocenicus Parodiz, 1949, del Eoceno de Patagonia (Parodiz, 1969; Miquel \& Bellosi, 2010). Otra forma citada para el Terciario, Bulimus neogaeus, constituye un nomen nudum (Doering, 1884c: 22), ignorándose a qué género pudiera asignarse dicha especie.

Especies con registros contínuos desde el Ensenadense hasta la actualidad son: Succinea meridionalis (centro y norte del país), Discoleus ameghinoi (sur de la provincia de Buenos Aires) y Plagiodontes daedaleus (centro del país). Por su parte, desde el Bonaerense a la fecha, se registran Bulimulus apodemetes, Spixia charpentieri y Scolodonta semperi. Las especies registradas exclusivamente en el Holoceno son: Gastrocopta nodosaria (d'Orb.), Retidiscus reticulatus Fonseca \& Thomé, Cecilioides consobrina (d'Orb.), Naesiotus deletangi (Parodiz), N. pollonerae (Ancey), Plagiodontes multiplicatus (Doering), Miradiscops brasiliensis (Thiele) y Epiphragmophora rhathymos (Holmberg).
En relación con la distribución geográfica, los registros abarcan sólo una parte del territorio argentino: áreas puntuales de las provincias de Buenos Aires, Córdoba, Entre Ríos, Mendoza, Santa Fe, Santiago del Estero y Tucumán (Fig. 1b). Pocas especies muestran desplazamientos geográficos a través del tiempo desde el Pleistoceno en Argentina: Megalobulimus globosus, Megalobulimus oblongus lorentzianus, Bulimulus rushii, Spixia spixii, Spixia charpentieri, Spixia tucumanensis, cuyos registros fósiles $v s$. actuales muestran ligeros cambios geográficos, durante el Bonaerense y el Platense, desplazados hacia el sur, abarcando el sector norte de la provincia de Buenos Aires.

En relación con el desplazamiento en la distribución geográfica de especies de gasterópodos continentales a través del tiempo, un ejemplo confirmado es la presencia de Bulimulus rushii en el Platense de Buenos Aires (MLP 8.262 de Maldonado, Buenos Aires); Frenguelli (1957) también menciona la presencia de Megalobulimus oblongus lorentzianus en el Bonaerense de Paraná y Parodiz (1969) señala los registros de Megalobulimus globosus en el Pleistoceno de Buenos Aires y de Spixia tucumanensis y $S$. charpentieri en el Bonaerense de Entre Ríos y Miramar, respectivamente. No se han encontrado en las colecciones revisadas materiales de estas especies con tales registros estratigráficos. Otros registros refieren la presencia de Spixia spixii spixii en el Bonaerense de Paraná (MLP 1.064 y MLP 1.328).

\section{AGRADECIMIENTOS}

A J. Aguirre, a C. De Francesco y a un revisor anónimo, las sugerencias y críticas recibidas; a los responsables de las colecciones estudiadas: C. Cingolani y Marta Alfaro (DCG-MLP), J. Merlo (FSC-IN-RQG), A. Tablado (MACN-In), C. del Río (MACN-Pi), G. Bahler (MAS PALEOINV), C. Damborenea (Invertebrados, MLP) y A. Riccardi (Paleoinvertebrados, MLP); a E. Tonni y a L. Cruz, por sus opiniones referidas a temas de estratigrafía; a F. Tricárico y A. Fussaro, del Servicio de Microscopía Electrónica y Fotografía del MACN y a G. del Fueyo, la obtención de las imágenes; a A. González la confección de ilustraciones gráficas y edición de fotografías; esta contribución fue financiada por la Universidad Nacional de La Plata (PI 11/ N587), la Agencia Nacional de Promoción Científica y Tecnológica (ANPCyT) (PICT468) y por el Consejo Nacional de Investigaciones Científicas y Técnicas (Conicet) (PIP 2010-0080). Los autores son los únicos responsables de los conceptos vertidos en la misma.

\section{REFERENCIAS}

Aguirre, M.L. \& Whatley, R.C. 1995. Late Quaternary Marginal Marine Deposits from North-Eastern Buenos Aires Province, Argentina: A Review. Quaternary Science Reviews, 14, 223-254.

Aguirre, M.L., Miquel, S.E., González, C. A., Kröhling, D., Zucol, A. F., Brea, M. \& Eastoe, C. 2011. Malacofauna 
continental holocena y paleoambientes en Villa Valle María (Diamante, Entre Ríos, Argentina). Geobios, 44, 1-17.

Albers, J.C. 1850.Die Heliceen, nachnatürlicher Verwandtschaft systematichgeordnetvonJohann ChristianAlber,Berlin, 1-262.

Ancey, C.F. 1897. Viaggio del Dott. Alfredo Borelli nel Chaco boliviano e nella Reppublica Argentina. XI. Résultats malacologuiques accompagnées d'une notice sur les espèces précédemment recueillis par ce voyageur. Bolletino dei Musei di Zoologia ed Anatomia Comparata della Reale Universitá di Torino, 12 (309), 1-22.

Andreis, R.R. 1977. Geología del Área de Cañadón Hondo, Depto. Escalante, provincia del Chubut, República Argentina. Revista del Museo de La Plata, Obra del Centenario, Geología, 4, 77-102.

Baker, H.B. 1925. The mollusca collected by the University of Michigan-Williamson Expedition in Venezuela, 3. Occasional Papers of the Museum of Zoology, 156, 1- 56.

Benson, W.H. 1856. New Land Shells collected by E.L. Layard. Annals and Magazine of Natural History, (2) 18 (108), 433-439.

Bequaert, J.C. 1948. Monograph of the Strophocheilidae, a Neotropical family of terrestrial mollusks. Bulletin of the Museum of Comparative Zoology, 100, 1-210, pls. 1-32.

Bouchet, P. \& Rocroi, J.-P. 2005. Classification and Nomenclator of Gastropod Families. Malacologia, 47 (1-2), 1-397.

Breure, A.S.H. 1976. Types of Bulimulidae (Mollusca, Gastropoda) in the Muséum National d'Histoire Naturelle, Paris. Bulletin du Muséum National d'Histoire Naturelle, (3) 331, Zoologie, 233, 1.137-1.187.

Breure, A.S.H. 1978. Notes on and descriptions of Bulimulidae (Mollusca, Gastropoda). Zoologische Verhandelingen te Leiden, 164, 1-255.

Breure, A.S.H. 1979. Systematics, Phylogeny and Zoogeography of Bulimulinae (Mollusca). Zoologische Verhandelingen te Leiden, 168, 1-215.

Breure, A.S.H. \& Coppois, G. 1978. Notes on the genus Naesiotus Albers, 1850 (Mollusca, Gastropoda, Bulimulidae). Netherlands Journal of Zoology, 28, 161-192.

Broderip, W. J. 1832. New species of shells collected by Mr. Cuming on the western coast of South America and in the islands of the South Paficic Ocean. Proceeding of the Zoological Society of London, 1832, 124-126.

Camacho, H.H. 1967 ("1966"). Invertebrados. In: Paleontografía bonaerense. 3 (Ed. A.V. Borrello). Comisión de Investigación Científica, La Plata, 1-159.

Castellanos, Z. J. A. de \& Landoni, N. A. 1995. Mollusca Pelecypoda y Gastropoda. In: Ecosistemas de Aguas Continentales. Metodologías para su estudio, 2 (Dirs. E.C. Lopretto \& G. Tell, Ed. Sur). La Plata, 759-801.

Cazzaniga, N.J. \& Delhey, V.K. 2002. Some observations on habitat and feeding of Plagiodontes patagonicus (d'Orbigny, 1835) (Gastropoda: Odontostomidae). V Congreso Latinoamericano de Malacología, São Paulo, Programa, Resúmenes y Anales, 233-234.

Cazzaniga, N.J., Pizá, J. \& Ghezzi, N.S. 2005. Intraspecific clinal variation in Plagiodontes patagonicus (Gastropoda: Orthalicidae, Odontostominae), an endemic species from Argentina. Journal of Natural History, 39 (24), 2.203-2.216.
Cione, A.L. \& Tonni, E.P. 2005. Bioestratigrafía basada en mamíferos del Cenozoico superior de la provincia de Buenos Aires, Argentina. In: Geología y Recursos Minerales de la Provincia de Buenos Aires (Eds. E.R de Barrio, M.F. Caballé \& E. Llambías). XVI Congreso Geológico Argentino, Relatorio, La Plata, 11, 183-200.

Crosse, J.C.H. \& Fischer, P.H. 1870-94. Études sur les Mollusques terrestres et fluviatiles du Mexique et du Guatemala. In: Mission Scientifique au Mexique et dans l'Amerique Centrale. Recherches Zoologiques, 7 (1) (Ed. M. Milne Edwards). Paris, 1-702.

Cuezzo, M.G. 1990. Gasterópodos pleistocénicos de la provincia de Tucumán. V Congreso Argentino de Paleontología y Bioestratigrafía, Tucumán, Actas 1, 199-204.

Cuezzo, M.G. 2006. Systematic revision and cladistic analysis of Epiphragmophora Doering from Argentina and Southern Bolivia (Gastropoda: Stylommatophora: Xanthonychidae). Malacologia, 49 (1), 121-188.

De Francesco, C.G., Zárate, M.A. \& Miquel, S.E. 2007. Late Pleistocene mollusc assemblages and inferred paleoenvironments from the Andean piedmont of Mendoza, Argentina. Palaeogeography, Palaeoclimatology, Palaeoecology, 251, 461-469.

Doering, A. 1873. Bemerkungen über die Mollusken-Fauna der Argentinischen Republik und über einige neue Argentinische Succineen. Malakozoologische Blätter, 21, 49-67, Taf. II-III (I-II).

Doering, A. 1874. Apuntamientos sobre la fauna de moluscos de la República Argentina. Boletín de la Academia Nacional de Ciencias Exactas en Córdoba, Buenos Aires, 1, 48-77.

Doering, A. 1875a ("1874"). Apuntes sobre la fauna de moluscos de la República Argentina (Segunda parte). Boletín de la Academia Nacional de Ciencias Exactas en Córdoba, Buenos Aires, 1 (4), 424-457.

Doering, A. 1875b (“1874”). Estudios sistemáticos y anatómicos sobre los moluscos pulmoníferos de los países del Plata. Periódico Zoológico, 1 (3), 129-204, lám. 4.

Doering, A. 1877 ("1875”). Apuntes sobre la fauna de moluscos de la República Argentina (continuación). Periódico Zoológico, 2 (4), 219-258.

Doering, A. 1878 ("1876"). Apuntes sobre la fauna de moluscos de la República Argentina (Tercera parte). Boletín de la Academia Nacional de Ciencias Exactas en Córdoba, 2, 300-339.

Doering, A. 1881. Moluscos. In: Informe oficial de la Comisión Científica agregada al Estado Mayor General de la Expedición al Río Negro (Patagonia) realizada en los meses de Abril, Mayo y Junio de 879 bajo las órdenes del General Julio A. Roca. I. Zoología. Buenos Aires, 61-75, lám. 1.

Doering, A. 1884a. Moluscos Pulmonata Stylommatophora. In: Holmberg, E.L. Viajes a las Sierras de Tandil y de La Tinta. Actas de la Academia Nacional de Ciencias en Córdoba, 5 (2), 111-115.

Doering, A. 1884b. Estudios hidrognósticos y perforaciones artesianas en la República Argentina. Boletín de la Academia Nacional de Ciencias en Córdoba, 6 (2), 319-340, lám. 2.

Doering, A. 1884c. Informe sobre un sedimento lacustre fosilífero encontrado en la perforación del Desaguadero 
(Ferro-carril Andino). Anales de la Sociedad Cientifica Argentina, 18, 5- 25.

Doering, A. 1885 (“1884"). Apuntes sobre la Fauna de Moluscos de la República Argentina. Boletín de la Academia Nacional de Ciencias de la República Argentina, 7, 457- 474 .

Doering, A. 1907. La formation pampéenne de Córdoba. In: Novelles recherches sur la Formation Pampéenne et l'homme fossile de la République Argentine (Ed. R. Lehmann- Nitsche). Revista del Museo de La Plata, 14, Segunda Serie, 1, 172-190, lám. 4.

d'Orbigny, A. 1834-1847. Voyage dans l'Amérique méridionale. 5 (3). Mollusques; 9. Atlas (Ed. P. Bertrand). Paris-Strasbourg, 1-758; 85 pls.

d'Orbigny, A. 1835. Synopsis terrestrium et fluviatilium molluscorum, in suo per Americam meridionalem itinere. Magasin de Zoologie, 5 (61), 1-44.

Draparnaud, J.P.R. 1801. Tableau des mollusques terrestres et fluviatiles de la France. Paris, 1-116.

Fernández, D. 1973. Catálogo de la malacofauna terrestre argentina. Monografías, 4 (Ed. Comisión de Investigaciones Científicas). La Plata, 1-197.

Férussac, A. E. J. P. J. F. d'Audebard de 1814. Mémoires géologiques sur les terreins formés sous l'eau douce par les débris fossiles des mollusques vivant sur la terre ou dans l'eau non salée. Paris, 1-76.

Férussac, A. E. J. P. J. F. d'Audebard de \& Deshayes, G.P. 1820 -1851. Histoire naturelle générale et particuliére des mollusques terrestres et fluviatiles, 1. Paris, 1-40.

Férussac, A. E. J. P. J. F. d'Audebard de \& Deshayes, G.P. 1821. Tableaux systèmatiques des animaux mollusques. Paris, 1-94.

Fonseca, A.L.M. da \& Thomé, J.W. 1995. A new genus and species of Charopidae (Gastropoda, Endodontoidea, Stylommatophora), Retidiscus reticulatus, from southern Brazil. Walkerana, 7 (17/18), 55-62.

Frenguelli, J. 1918. Sobre un Borus enano procedente de la Sierra Alta de Córdoba. Boletín de la Academia Nacional de Ciencias en Córdoba, 23, 228-231.

Frenguelli, J. 1920. Contribución al conocimiento de la geología de Entre Ríos. Boletín de la Academia Nacional de Ciencias en Córdoba, 24, 55-256.

Frenguelli, J. 1923. Conchas de "Borus". Boletín de la Academia Nacional de Ciencias en Córdoba, 26, 404-418.

Frenguelli, J. 1939. La Serie geológica de la República Argentina en sus relaciones con la antigüedad del Hombre. In: Historia de la Nación Argentina 1 (Ed. Academia Nacional de la Historia), Buenos Aires, 3-18.

Frenguelli, J. 1957. Neozoico. In: Geología de la República Argentina, 2 (3) (Ed. Sociedad Argentina de Estudios Geográficos), Buenos Aires, 1-115.

Genise, J.F., Melchor, R.N., Bellosi, E.S. \& Verde, M. 2010. Invertebrate and Vertebrate Trace Fossils from Continental Carbonates. In: Developments in Sedimentology, 61 (7) (Ed. A.M. Alonso-Zarza \& L.H. Tanner), 319-369.

Gmelin, J. F. 1788-1792. Systema naturae. Ed. XIII, aucta reformata, I. Lipsiae, 1-4120.

Heller, J., Pimstein, R. \& Vaginsky, E. 1991. Cave-dwelling
Cecilioides genezarethensis (Pulmonata, Ferussaciidae) from Israel. Jounal of Molluscan Studies, 57, 289-300.

Hidalgo, J.G. 1869. Description d'espéces nouvelles. Journal de Conchyliologie, (3) 9, 410-413.

Hidalgo, J.G. 1870. Catalogue des Coquilles terrestres recueillies par les naturalistes de la commission scientifique espagnole sur divers points de l'Amérique méridionale. Journal de Conchyliologie, (3) 9 (18), 27-70, pls. 1, 6.

Holmberg, E.L. 1912. Moluscos argentinos en parte nuevos, coleccionados por Franco Pastore. Physis, 1, 19-26.

Hylton Scott, M.I. 1939. Estudio anatómico del borus Strophocheilus lorentzianus (Doer.) (Mol. Pulm.). Revista del Museo de La Plata (nueva serie), Zoología, 1, 217-278.

Hylton Scott, M.I. 1948. Moluscos del noroeste argentino. Acta Zooógica. Lilloana, 6, 241-274.

Hylton Scott, M.I. 1963. Moluscos terrestres y de agua dulce de la Patagonia. In: Biologie de l'Amérique Australe, 2. Études sur la faune du sol (Dirs. Cl. Delamare Debouteville \& E. Rapoport; Ed. Centre National de la Recherche Scientifique y Consejo Nacional de Investigaciones Científicas y Técnicas). Paris, 385-398.

Hylton Scott, M.I. 1968. Répartition et biogéographie des Mollusques de Patagonie. In: Biologie de l'Amérique Australe, 4. Études sur la faune du sol. Documents biogéographiques. (Dirs. Cl. Delamare Debouteville \& E. Rapoport; Ed. Centre National de la Recherche Scientifique y Consejo Nacional de Investigaciones Científicas y Técnicas). Paris, 269-273.

Ihering, H. von 1907. Les mollusques fossiles du Tertiaire et du Crétacée Supérieur de l'Argentine. Anales del Museo Nacional de Buenos Aires, 14, 1-611.

Ihering, H. von 1908. Mollusques du pampéen de Mar del Plata et Chapadmalal. Anales del Museo Nacional de Buenos Aires, 17 (3), 10, 429-438.

Ihering, H. von 1914. Catálogo de moluscos Cretáceos e Terciarios de Argentina da colleção do author. Notas Preliminares da revista do Museu Paulista, 1 (3), 1-148.

Kidwell, S.M., Fürsich, F.T. \& Aigner, T. 1986. Conceptual Framework for the Analysis and Classification of Fossil Concentrations. Palaios, 1, 228-238.

King, P.P. \& Broderip, J. 1831. Description of the Cirripedia, Conchifera and Mollusca....Zoological Journal, 5, 332-349.

Klappenbach, M.A. 1989. Notas sobre Strophocheilidae. VII. Contribución al conocmiento de Austroborus cordillerae (Doering, 1876) (Moll. Gastropoda). Comunicaciones Zoológicas del Museo de Historia Natural de Montevideo, 12 (170), 1- 11.

Klappenbach, M.A. \& Olazarri, J. 1973. El género Scalarinella Dohrn, 1874 (Moll. Gastropoda) en el Uruguay. In: $V$ Congreso Latinoamericano de Zoología, Montevideo, Trabajos, 1, 111-116.

Leach, W.E. 1814. Zoological miscellany...1. London, 1 - 144. Martens, E. v. 1877. Die Bulimus-Artenaus der Gruppe Borus. In: Novitates Conchologicae. Series Prima. Mollusca extramarina, 5, 1-26, Taf. 138-141.

Matthews, S.C. 1973. Notes on Open Nomenclature and on Synonymy Lists. Palaeontology, 16 (4), 713-719.

Melchor, R.N., Genise, J.F. \& Miquel, S.E. 2002. Icnology, 
sedimentology and paleontology of Eocene calcareous paleosols from a palustrine sequence, south west La Pampa, Central Argentina. Palaios, 17, 16-35.

Miller, K. 1878. Die Binnenmollusken von Ecuador. Malakozoologische Blätter, 25, 153-199, pls. 7-8.

Miquel, S.E. 1989. Las especies vivientes del género Naesiotus Allbers, 1860 en la República Argentina (Mollusca, Gastropoda, Stylommatophora). Studies on Neotropical Fauna and Environment, 24 (2), 61-73.

Miquel, S.E. 1991. El género Bulimulus Leach, 1814 (Mollusca, Gastropoda, Stylommatophora) en la República Argentina. Studies on Neotropical Fauna and Environment, 26 (2), 93-112.

Miquel, S.E. 1998. Redescription of Argentinean species of the genera Discoleus, Plectostylus, Scutalus and Simpulopsis (Gastropoda Stylommatophorida Bulimulidae). Studies on Neotropical Fauna and Environment, 33, 178-187.

Miquel, S.E. \& Bellosi, E.S. 2007. Microgasterópodos terrestres (Charopidae) del Eoceno medio de Gran Barranca (Patagonia Central, Argentina) y su relación con los cambios ambientales de la transición Eoceno-Oligoceno. Ameghiniana, 44, 121-131.

Miquel, S.E. \& Bellosi, E.S. 2010. Middle Eocene - Oligocene gastropods of the Sarmiento Formation, central Patagonia. In: The Paleontology of Gran Barranca (Ed. R.H. Madden, A.A. Carlini, M.G. Vucetich \& R.F. Kay. Cambridge University Press). New York, 61-68.

Miquel, S.E. \& Cádiz Lorca, F.J. 2009. Araucocharopa gallardoi gen. et sp. $n$. de Charopidae (Mollusca: Gastropoda: Stylommatophora) del sur de Chile. Revista del Museo Argentino de Ciencias Naturales, n.s., 10 (2), 329-340.

Miquel, S.E. \& Manceñido, M. O. 1999. First Miocene record of fossil Strophocheilidae (Gastrop. Stylomm. Acavoidea) from Patagonia (Argentina). Ameghiniana, 36 (3), 311-316.

Miquel, S.E. \& Parent, H. 1997 (“1996”). Moluscos Gasterópodos de la provincia de Santa Fe (Argentina). Malacological Review, 29, 107-112.

Miquel, S.E. \& Steffan, P. 2005. Retidiscus reticulatus Fonseca \& Thomé (Gastropoda, Pulmonada, Charopidae) en la Argentina: un posible indicador de paleoclima subtropical húmedo en el Holoceno de la provincia de Buenos Aires. Ameghiniana, 42 (2), 495-500.

Miquel, S.E., Ramírez, R. \& Thomé, J.W. 2007. Biodiversidad y taxonomía de micromoluscos Punctoidea del sur de Brasil, con la descripción de una nueva especie de Radiodiscus de la Mata Atlántica (Mollusca, Gastropoda, Pulmonata). Revista del Museo Argentino de Ciencias Naturales (Nueva serie), 9 (2), 205-230.

Morton, L.S., 1999. El género Radiodiscus (GastropodaEndodontidea) en el Cretácico temprano, provincia de Santa Cruz, Argentina. Geociências, 4 (6), 46-49.

Müller, O.F. 1774. Vermiun terrestrium et fluviatilium seu animalium Infusiorum, Helminthicorum et Testaceorum, non marinorum, succinta historia, 2. Havniae et Lipsiae, $1-214$.

Oliveira, M. P. de \& de Oliveira, M. H. R. 1974. Dicionário conquílio malacológico. (Ed. Universidade Federal de Juiz de Fora). Juiz de Fora, 5-190.
Parodiz, J.J. 1939. Revisión de Plagiodontes y Scalarinella. Physis, 17, 711-734.

Parodiz, J.J. 1941. Four new species of Spixia from Argentina. Nautilus, 54, 92-95.

Parodiz, J.J. 1942. Los Odostostominos de la Argentina (Segunda parte). Physis, 19, 319-343.

Parodiz, J.J. 1946a. Contribuciones al conocimiento de los moluscos terrestres sudamericanos, 4. Comunicaciones Zoológicas del Museo de Historia Natural de Montevideo, 2 (27), 1-14.

Parodiz, J.J. 1946b. Los géneros de Bulimulinae de la Argentina. Revista del Museo de La Plata, Zoología, 4, 303-371.

Parodiz, J.J. 1949a. Un nuevo gastrópodo terrestre del Eoceno de Patagonia. Physis, 20 (57), 174-179.

Parodiz, J.J. 1957. Catalogue of the land Mollusca of Argentina. Nautilus, 70 (4), 127-135.

Parodiz, J.J. 1962. New and little-known species of South and Central American land snails (Bulimulidae). Proceedings of the United States of Natural Museum, 113, 429-456.

Parodiz, J.J.1969. The Tertiary non-marine Mollusca of South America. Annals of Carnegie Museum, 40, 1-242.

Parodiz, J.J. 1996. The taxa of fossil Mollusca introduced by Hermann von Ihering. Annals of Carnegie Museum, 65 (3), 183-296.

Pfeiffer, L. 1851 (“1850”). Neue Landschnecken. Zeitzchrift für Malakozoologie, 8 (1), 13-15.

Pfeiffer, L. 1866. Beschreibung neuer Landschnecken. Malakozoologische Blätter, 13, 76-91.

Pfeiffer, L. 1877. Monographia Heliceorum Viventium, 8 (Ed. F. A. Brockhaus). Lipsiae, 1-729.

Pilsbry, H.A. 1894. Guide to the study of Helices. Manual of Conchology, (2) 9. Philadelphia, 1-366, 71 pls.

Pilsbry, H.A. 1897a. Descriptions of new South American Bulimuli. Proceedings of the Academy of Natural Sciencies of Philadelphia, 49, 18-22.

Pilsbry, H.A. 1897b-1898. American Bulimulidae: Bulimulus, Neopetraeus, Oxychona and South American Drymaeus. Manual of Conchology, (2) 11. Philadelphia, 1- 399.

Pilsbry, H.A. 1901-02. Oriental bulimoid Helicidae; Odontostomidae; Cerionidae. Classification of Bulimulidae and index to volumes 10-14. Manual of Conchology, (2) 14 Philadelphia, 1-302.

Pilsbry, H.A. 1916. Manual of Conchology, (2) 24 (93). Philadelphia, 1-112.

Pilsbry, H.A. 1926a. South American Land and Fresh Water Mollusks: Notes and Descriptions. Proceedings of the Academy of Natural Sciencies of Philadelphia, 78, 1-15, 2 pls.

Pilsbry, H.A. 1926b. Costa Rican land shells collected by A. A. Olsson. Proceedings of the Academy of Natural Sciencies of Philadelphia, 78, 127-133, pl. 11.

Pilsbry, H.A. 1948. Land Mollusca of North America (north of Mexico). Monographs, 3. Academy of Natural Sciences of Philadelphia. Philadelphia, 1-1113.

Pilsbry, H.A. \& Ferriss, J.H. 1906. Mollusca of the Southwestern States. II. Proceedings of the Academy of Natural Sciencies of Philadelphia, 58, 123-175.

Pilsbry, H.A. \& Rush, W. H. 1896. List, with notes, of land 
and fresh water shells collected by Dr. Wm. H. Rush in Uruguay and Argentina. Nautilus, 10 (7), 76- 81.

Pilsbry, H.A. \& Vanatta, E. G. 1898. Materials toward a natural classification of the cylindrelloid snails. Proceedings of the Academy of Natural Sciencies of Philadelphia, 50, 264-286, pls. 17-18.

Pizá, J. \& Cazzaniga, N.J. 2003. Redescription, shell variability and geographic distribution of Plagiodontes dentatus (Wood, 1828) (Gastropoda: Orthalicidae: Odontostominae) from Uruguay and Argentina. Zootaxa, 154, 1-23.

Prieto, A. R., Vilanova, I. \& De Francesco, C.G. 2003. Estratigrafía y paleoecología del Pleistoceno tardío - Holoceno del área del arroyo Las Brusquitas, Buenos Aires, Argentina: una revisión. In: Collantes, M., J. M. Sayago \& L. del V. Neder, eds. II Congreso Argentino de Cuaternario y Geomorfología, Tucumán, Actas, 47-56.

Prieto, A.R., Blasi, A.M., De Francesco, C.G. \& Fernández, C. 2004. Environmental history since $11,00014 \mathrm{C}$ yr B.P. of the northeastern Pampas, Argentina, from alluvial sequences of the Luján River. Quaternary Research, 62, 146-161.

Rafinesque, C. S. 1833. New genera of land shells from Buenos Aires, South America. Atlantic Journal Friend of Knowledge, 5, 165.

Riccardi, A.C. 2007. Terciario y Cuaternario: definición y posición. Revista de la Asociación Geológica Argentina, 62 (3), 485-487.

Ringuelet, R.A. 1961. Rasgos fundamentales de la Zoogeografía de la Argentina. Physis, 22, 151-170.

Salas Oroño, M.E. 2007. Taxonomic review of the Spixia pyriformis species complex (Gastropoda: Plumonata: Odontostominae). Zootaxa, 1.498, 1-25.

Scopoli, J.A. 1786-88. Deliciae Florae et Faunae Insubricae seu novae, aut minus cognitae species plantarum et animalium quas in Insubria Austriaca tam spontaneas, quam exoticas vidit, descripsit, et aeri incidi curavit Joannes Antonius Scopoli. Tinici.

Simone, L.R.L. 2006. Land and Freshwater Molluscs of Brazil. (Ed. EGB, Fapesp). São Paulo, 390 pp.

Simone, L.R.L. de \& Mezzalira, S. 1994. Fossil Molluses of Brazil. Boletim, 11 (Ed. Instituto Geológico. Secretaria do Meio Ambiente). São Paulo, 202 pp.

Sowerby, G.B. 1820-34. The genera of recent and fossil shells... I, II. London, 267 pls.

Spix, J.B. de 1827. Testacea fluviatilia quae in itinere per brasiliam... (Ed. P. De Schrank \& C. De Martius). Lipsiae, 1-36.

Strobel, P. 1874. Materiali per una malacostatica di terra e di acqua dolce dell'Argentina meridionale (Ed. Biblioteca malacologica). Pisa, 1-79.

Stuardo, J. \& Vega, R. 1985. Synopsis of the Land Mollusca of Chile. With Remarks on Distribution. Studies on Neotropical Fauna and Environment, 20 (3), 125-146.

Tablado, A. \& Mantinian, J. 2004. Catálogo de ejemplares tipo de la División Invertebrados del Museo Argentino de Ciencias Naturales. II. Mollusca. Revista del Museo Argentino de Ciencias Naturales, n.s., 6 (2), 363-384.

Thiele, J., 1927. Über einige brasilianische Landschnecken. Abhandlungen der Senckenbergischen Naturforschennden Gesellschaft, 40 (3), 307-329, Taf. 26.
Tonni, E. P. 2004. Fauna y clima en el Cuaternario de la Mesopotamia. In: Temas de la Biodiversidad del Litoral fluvial argentino (Coord.-Ed. F. G. Aceñolaza). INSUGEO, Miscelánea, 12, 31-38.

Tonni, E.P. 2009. Los mamíferos del Cuaternario de la región pampeana de Buenos Aires, Argentina. Quaternário do Rio Grande do Sul integrando conhecimentos. In: Monografias (Org. A.M.Riberiro, S.G. Bauermann \& C.S. Scherer; Ed. Sociedade Brasileira de Palentologia), Porto Alegre, 193-205.

Tonni, E.P., Cione, A.L. \& Figini, A. 1999. Predominance of arid climates indicated by mammals in the pampas of Argentina during the Late Pleistocene and Holocene. Palaeogeography, Palaeoclimatology, Palaeoecology, 147, 257-281.

Tonni, E. P., Cione, A. L., Figini, A. J., Noriega, J. I., Carlini A. A. \& Miquel S. E., 2001. Extensión del período árido del Holoceno hasta los siglos X a XIII basada en el registro de moluscos terrestres en Entre Ríos (Argentina). XI Congreso Latinoamericano de Geología y III Congreso Uruguayo de Geología, Montevideo, Actas: 1-5. Versión electrónica.

Tracey, S., Todd, J.A. \& Erwin, D.H. 1993. Mollusca: Gastropoda. The Fossil Record. 2 (Ed. M.J. Benton. Chapman \& Hall). London, 131-167.

Tryon, G.W. 1867. Monograph of the terrestrial mollusca of the United States. American Journal of Conchology, 3 (2), 155-181, pls. 11-14.

Tryon, G.W. 1885. Testacellidae, Oleacinidae, Streptaxidae, Helicoidea, Vitrinidae, Limacidae, Arionidae. Manual of Conchology. 1. Philadelphia, 1- 364, 60 pls.

Tryon, G.W. 1888. Helicidae. 2. Manual of Conchology, 4. Philadelphia, 1-296, pls. 69.

Vargas-Almonacid, P. 2000. Nueva especie de microgastrópodo humícola para Chile, Radiodiscus quillajicola spec. nov. (Stylommatophora Charopidae). Gayana, 64, 61-66.

Voglino, D. \& Pardiñas, U.J. 2005. Roedores sigmodontinos (Mammalia: Rodentia: Cricetidae) y otros micromamíferos pleistocénicos del norte de la provincia de Buenos Aires (Argentina): reconstrucción paleoambiental para el Ensenadense cuspidal. Ameghiniana, 42 (1), 143-158.

Weyrauch, W.K. 1965. Neue und verkannte Endodontiden aus Südamerika. Archiv für Molluskenkunde, 94 (3/4), 121-134.

Wollaston, T.V. 1878. Testacea Atlantica or the land and freshwater shells of the Azores, Madeiras, Salvages, Canaries, Cape Verdes, and Saint Helena. London, 1-588.

Wood, W., 1828. Index testaceologicus. supplement. i-iv. London, 1-59.

Zilch, A. 1959-60. Gastropoda Euthyneura. In: Handbuch der Paläozoologie 6 (2) (Ed. O.H. Schindewolf), BerlinNikolassee, 834 pp.

Zilch, A. 1971. Die Typen und Typoiden des Natur-Museums Senckenberg 47: Mollusca-Euthyneura von A. Döring aus Argentinien. Archiv für Molluskenkunde, 101, 195-213.

Manuscrito recibido: 3 de Marzo, 2011 Manuscrito aceptado: 7 de Noviembre, 2011 


\section{APÉNDICE}

Abertura: espacio de la concha por donde emerge el complejo céfalo-pedal del gasterópodo.

Altura: distacia entre el ápice y el borde basal de la concha, ubicada ésta en forma vertical.

Anfracto: véase vuelta.

Ápice: en latín apex. Extremo de la concha, opuesto a la abertura, ocupado por la protoconcha.

Callo: excrecencia calcárea depositada por el manto sobre la columela de conchas enroscadas, típicamente en ejemplares adultos y, especialmente, durante períodos de hibernación.

Columela: columna. Eje que origina el giro de las conchas enroscadas durante su crecimiento.

Costilla: listón. Estructura conquiliar sobresaliente, ubicada en las superficies externa o interna de la concha, de forma alargada.

Cóstula: costilla de relieve mucho más bajo, tanto en la protoconcha como en la teleoconcha.

Diámetro mayor (o máximo): distancia entre los bordes de la concha, tomada perpendicular a la altura.

Diente o dentículo: estructura de forma acuminada ubicada en la faz interna de la concha, pudiendo ser visible desde el exterior o no.

Escultura: conjunto de estructuras de la superficie de la concha (costillas, cóstulas, surcos y líneas axiales y / o radiales).

Espira: conjunto de las vueltas de una concha enroscada, con excepción del último anfracto o vuelta.

Incisuras: hendidura. Véase líneas.
Labio: borde del peristoma, puede ser interno (borde columelar) o externo (labro).

Labro: borde externo del peristoma.

Lamela: estructura calcárea en forma de pequeña lámina o placa que suele obturar, parcialmente, la abertura de la concha.

Línea: incisuras. Rayas o marcas poco profundas que cubren la concha.

Línea de crecimiento: marcas en relieve, normalmente irregulares, que dependen del crecimiento del animal, paralelas al labro.

Ombligo: espacio determinado por el crecimiento no coalescente de las vueltas. Generalmente visible, puede ser perspectivo (cuando se pueden observar las paredes internas de las vueltas) o no perspectivo.

Perióstraco: lámina orgánica (proteica) de conquiolina que cubre a la concha.

Peristoma: bordes de la abertura, el que puede "reflejarse", es decir, crecer en empalizada.

Protoconcha: concha embrionaria, que puede tener diferente escultura que la teleoconcha. El algunas especies se desprende, al formarse un septo calcáreo por debajo.

Surco: hendidura o línea más profunda y ancha en la superficie externa de la concha.

Sutura: línea de unión o coalescencia de dos vueltas.

Teleoconcha: concha adulta.

Vuelta: dícese del giro de la concha; que se mide, habitualmente, por cuartos $(1 / 4$ ó 0,25$)$. 
Apellidos

Last name

Título/Title

Fax:

Nombre

First name

Tlfno.:

(dirección/address)

C.P.

Ciudad

País

Zip Code

City/State

Country

(temas; edades; área geográfica / fields; ages; geographic area

Solicita ser admitido en la Sociedad Española de Paleontología como:

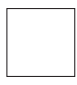

Socio ordinario
Ordinary membership

Cuota 2012
2012 Dues $\{50$ euros

Fecha de nacimiento

Birth date

$\begin{array}{ll}\text { Socio estudiante (menores de } 27 \text { años) } & \text { Cuota } 2012 \\ \text { Student membership (under } 27 \text { years old) } & 2012 \text { Dues }\end{array}\{20$ euros

Fecha y Firma

$\square$

Date and Signature

Socio corporativo

Cuota 2012

Institutional membership

2012 Dues

$\{80$ euros

(nombre del Centro / Institution name)

Presentado por/Presented by

(dos socios/two members)

Certificación de la condición de estudiante (sólo para socios estudiantes)

Certification of student status (for student members only)

Certifico que el solicitante es

estudiante/doctorando en el

Dpto. de

de la

(institución)
I certify that the above-named is a full-time undergraduate/postgraduate student in the

Dept. of

at

Fecha y firma/Date and signature (institution)

(nombre y título / full name and title)

Enviar una copia a: Send a copy to:
Secretaría de la Sociedad Española de Paleontología Museo Nacional de Ciencias Naturales

C/. José Gutiérrez Abascal, 2

E-28006 MADRID

ESPAÑA/SPAIN 